University of San Diego

Digital USD

2009-08-01

\title{
Restoring Confidence: A Qualitative Study of the Experience of Interim Commanding Officers in U.S. Navy Operational Units
}

Shoshana S. Chatfield EdD

University of San Diego

Follow this and additional works at: https://digital.sandiego.edu/dissertations

Part of the Leadership Studies Commons

\section{Digital USD Citation}

Chatfield, Shoshana S. EdD, "Restoring Confidence: A Qualitative Study of the Experience of Interim Commanding Officers in U.S. Navy Operational Units" (2009). Dissertations. 791.

https://digital.sandiego.edu/dissertations/791

This Dissertation: Open Access is brought to you for free and open access by the Theses and Dissertations at Digital USD. It has been accepted for inclusion in Dissertations by an authorized administrator of Digital USD. For more information, please contact digital@sandiego.edu. 


\title{
RESTORING CONFIDENCE: \\ A QUALITATIVE STUDY \\ OF THE EXPERIENCE OF INTERIM COMMANDING OFFICERS \\ IN U. S. NAVY OPERATIONAL UNITS
}

\author{
by \\ SHOSHANA S. CHATFIELD \\ A dissertation submitted in partial fulfillment \\ of the requirements for the degree of \\ Doctor of Education \\ University of San Diego
}

August 2009

Dissertation Committee

Dr. Mary Woods Scherr, Ph.D., Chair

Dr. Robert Donmoyer, Ph.D.

Dr. Port R. Martin, Ed.D. 
(C) Copyright by Shoshana S. Chatfield 2009

All Rights Reserved 


\begin{abstract}
Commanding officers in the United States Navy are entrusted by law with absolute authority, responsibility, and accountability. Despite a rigorous selection process, some commanding officers are relieved of command every year. In many cases, these commanding officers are replaced by interim commanding officers, leaders selected to fill the job for short periods of time. There is a gap in leadership literature about the phenomenon of interim command leadership in the Navy. This study investigated interim commanding officers' experiences of taking command following the deliberate removal of the unit's previous commanding officer.
\end{abstract}

A review of current literature on the subjects of command at sea, leadership, organizational culture, and leading planned change in organizations was conducted to develop a basis for understanding existing theories about challenges facing incoming leaders, effective leadership behaviors to generate change within an organization, and recommended strategies for effecting organizational change.

A qualitative research methodology was used to provide rich detail about the experiences of interim commanding officers and to develop theories grounded in the data. Eleven former Navy interim commanding officers were interviewed to obtain data to answer the following research questions: (1) What were the experiences and leadership challenges faced by interim commanding officers? (2) Which experiences, if any, differed from their first command tour? (3) What observations were made by interim commanding officers about the organizational culture and morale of the wardroom upon their arrival and departure from the unit? (4) Which leadership behaviors and strategies, if 
any, did interim commanding officers find useful to change the organizational culture and morale of the wardroom?

The findings suggested that: (a) interim commanding officers experienced a higher degree of confidence entering the assignment than on their first command tour, (b) the unknown and not knowing who among the crew they could trust were challenges, (c) effects on the wardroom varied with severity of the incident, the crew's perceived association with the event, and remoteness factors, and (d) that by modeling desired behaviors and focusing on communication, interim commanding officers restored confidence in leadership and mission readiness to the wardroom, the crew and external stakeholders. 


\section{DEDICATION}

To the Sailors I have met along the way who placed their trust in me. 


\section{ACKNOWLEDGMENTS}

Special thanks go to my family and all my friends for supporting me during this epic quest. I am grateful for my wonderful friend and editor, Kathy, who dropped everything to proofread my drafts, and help me recover my sanity, twice! Thanks, Kathy for the commas, which's and who's. If there are any mistakes in this document it is because I didn't heed your recommendations when I should have.

As much penance as pursuit, the journey itself was more important to me than earning a degree. I give special recognition to the original cohort of Navy colleagues who began the Leadership Studies program with me. The intensive pace of that first year and our enthusiasm and energy for the material sustained me through to the end. Thanks go to our gifted professors from USD and SDSU, who made the trek down to the Navy base to guide our learning, and to the Leadership Studies Department Chair, Dr. Cheryl Getz, who found every way to support me in the program through my four moves, five jobs and two deployments. I could not have finished this dissertation or the doctoral program without the reassuring help of Beth Yemma, Kate Sheridan, and Annie Guanciale, the administrative staff at USD School of Leadership and Education Sciences. Thanks so much for helping me overcome the great distances, remote access and connectivity problems I had during my time overseas. My grateful appreciation also goes to my Dissertation Chair, Dr. Mary Scherr, whose advice and example I will always cherish, and my committee members, Dr. Bob Donmoyer and Dr. Bob Martin whose wisdom and wit I will miss. I wish I had recorded every word! Thanks for keeping the faith.

I would like to also recognize General Jack Galvin (USA, Retired) who, as Dean of the Fletcher School of Law and Diplomacy, taught the first course I took on leadership 
which sparked my interest in the subject. I would also like to thank Rear Admiral Mark Guadagnini, USN, whose support bought me the time and space to advance to candidacy and write this dissertation. I also thank Rear Admiral Nora Tyson, USN, and Admiral Mike Mullen, USN, who understood how much this dissertation meant to me and gave me the opportunity to launch it.

I must conclude with words of awe and appreciation for the men who participated in this study. Thank you so much for granting me an interview and for sharing your experiences and wisdom with me. Most of all, thank you for what you did for our Navy and nation! 


\section{TABLE OF CONTENTS}

LIST OF TABLES

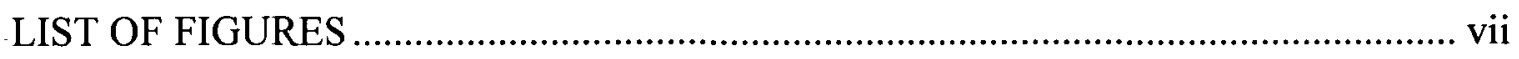

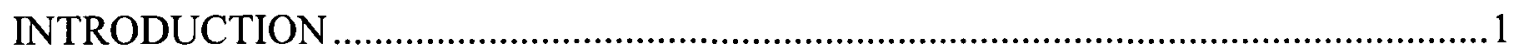

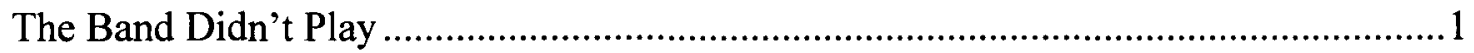

\section{CHAPTER}

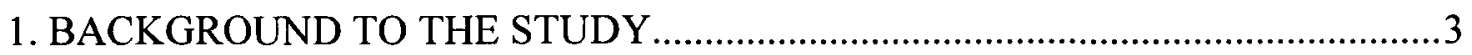

Commanding Officers in the U. S. Navy................................................................

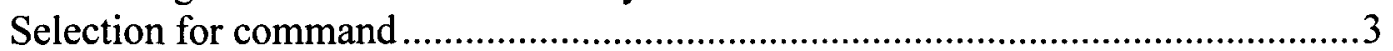

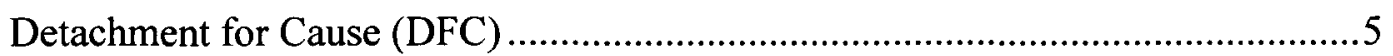

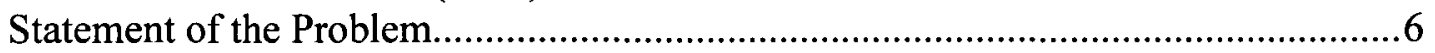

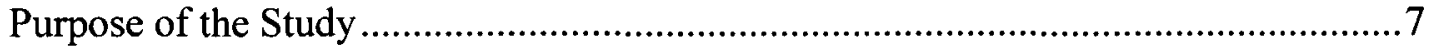

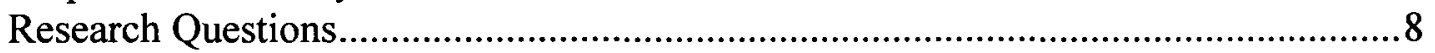

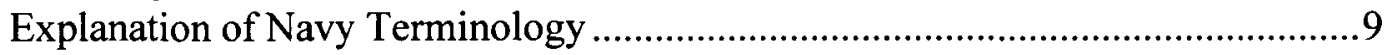

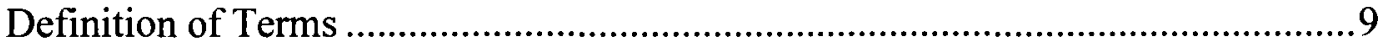

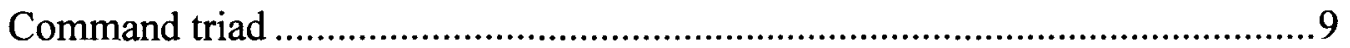

Interim commanding officer ...........................................................................

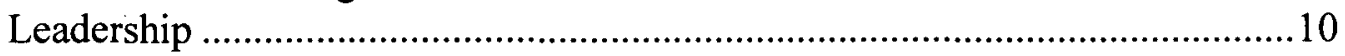

Higher levels of leadership ........................................................................... 10

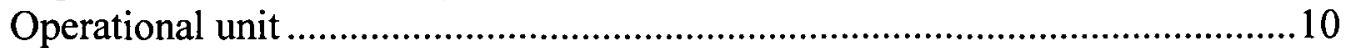

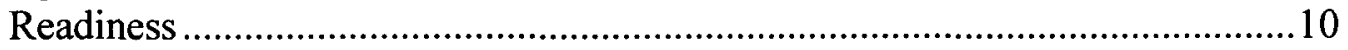

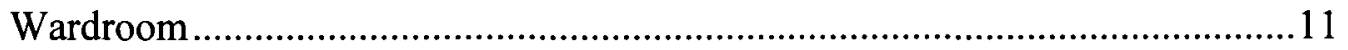

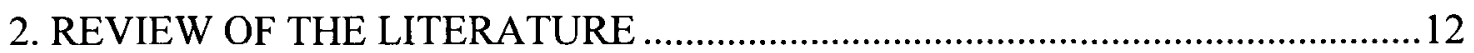

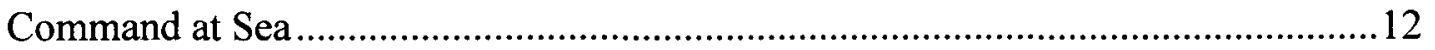

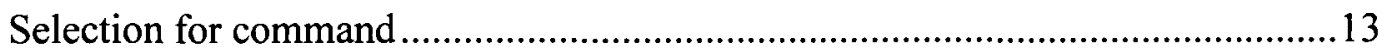

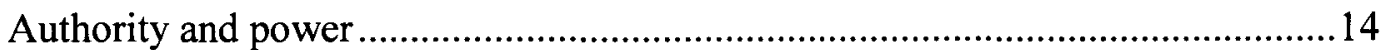

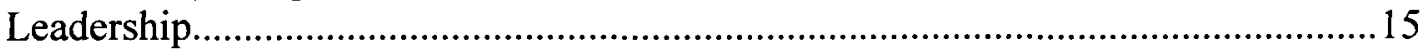

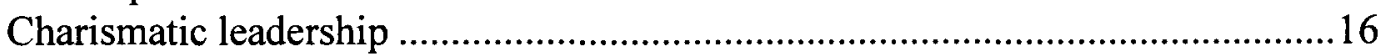

Leader and follower relationship ....................................................................17

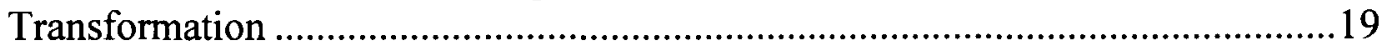

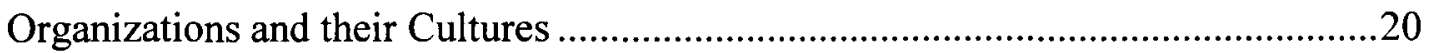

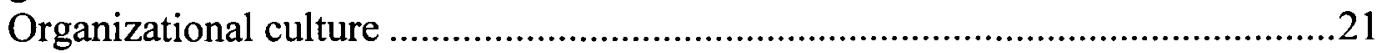

Group Cohesiveness ………………...........................................................22

Leading Planned Change ...................................................................................23

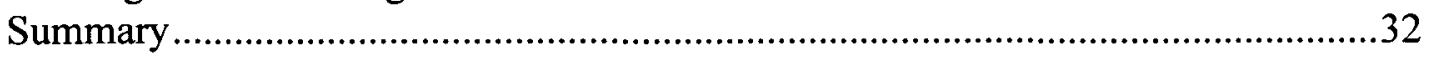




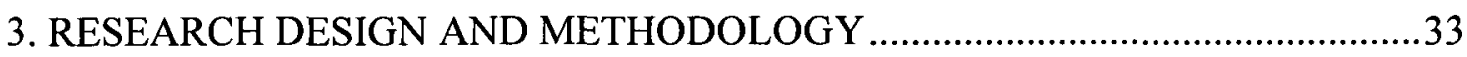

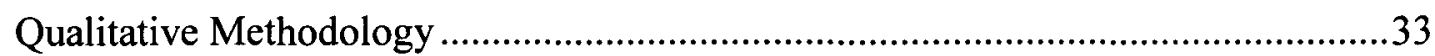

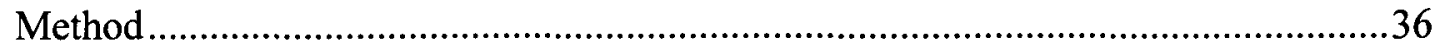

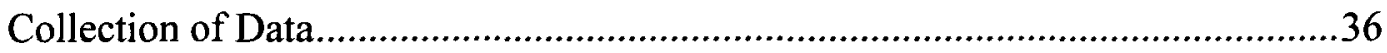

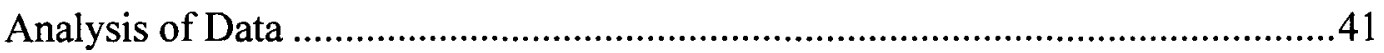

Delimitations and Limitations ............................................................................43

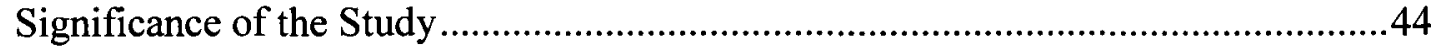

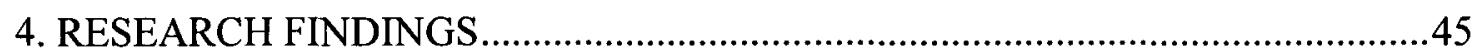

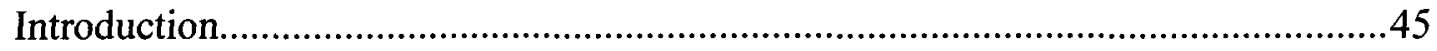

The Experience of Being an Interim Commanding Officer ......................................45

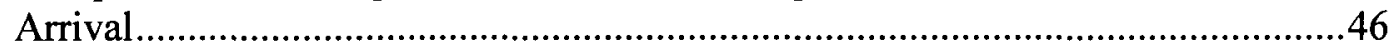

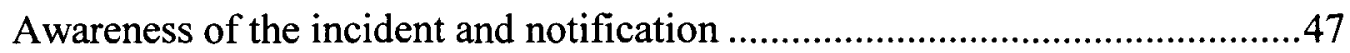

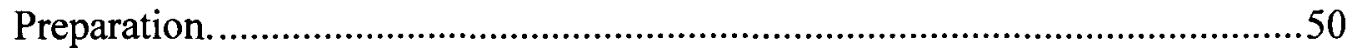

Arrival at the unit and incoming change of command. ....................................53

Interim Command Leadership ..........................................................................56

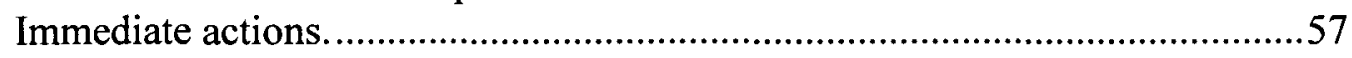

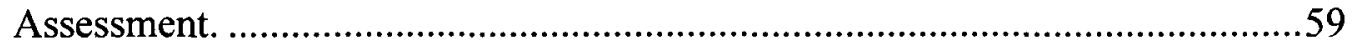

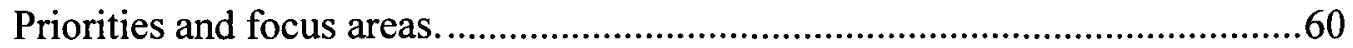

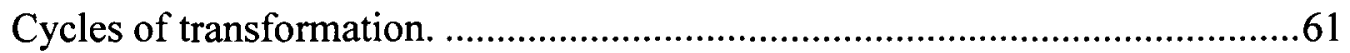

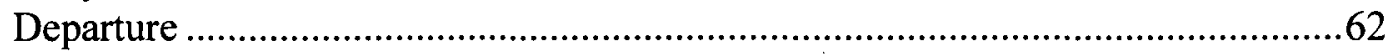

Outgoing Change of Command......................................................................63

Personal interpretations of the experience (Internalization)..............................64

A Model of Restoring Confidence through Interim Leadership................................65

Leadership Challenge: Dealing with the Unknown............................................66

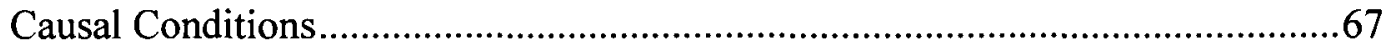

Desire to mitigate effects of the event or incident..........................................68

Desire to mitigate effects of the removal of the previous commanding officer.

.

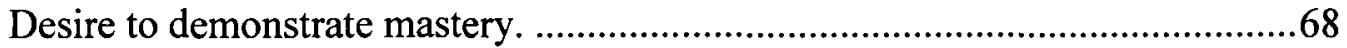

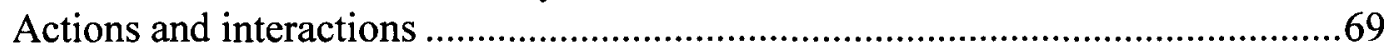

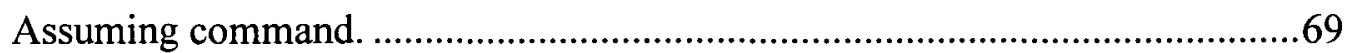

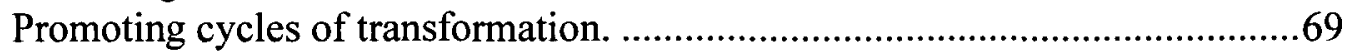

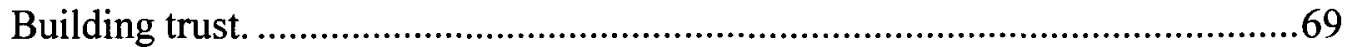

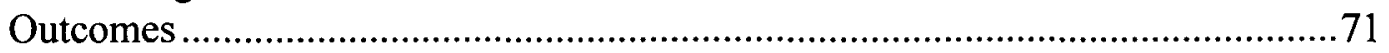

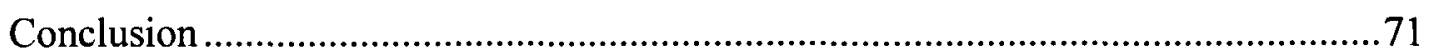

5. DISCUSSION

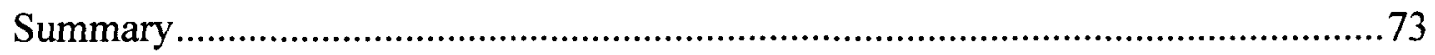

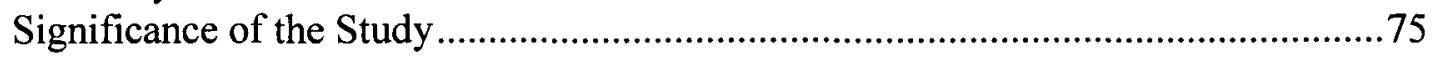

Research Question (a): Experience and Challenges ...............................................76

Research Question (b): Comparison with First Command Tour............................77

Research Question (c): Observations about wardroom culture and morale ...........79

Research question (d): Changing wardroom culture and morale ............................8

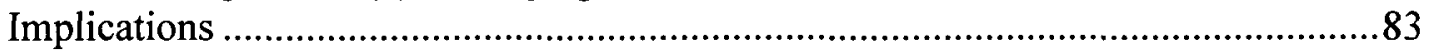

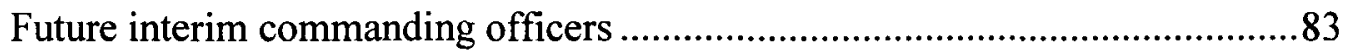




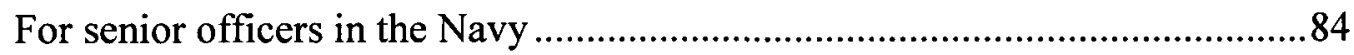

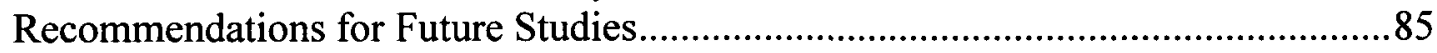

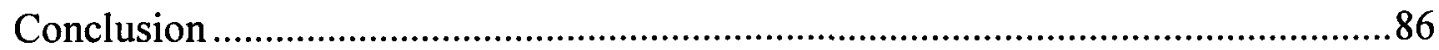

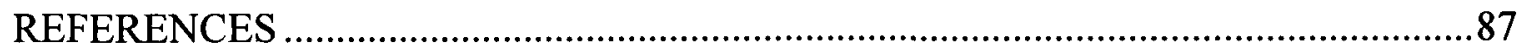

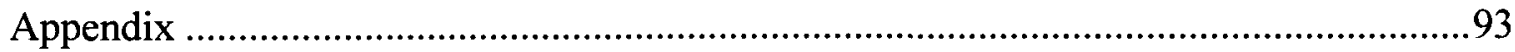

A. Research Participant Consent Form...............................................................94

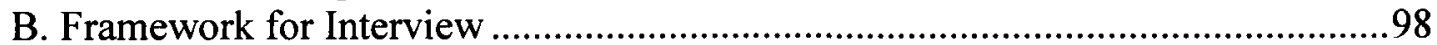

C. Framework of Interim Commanding Officer Experience....................................100

D. Justifications for Assignment of an Interim Commanding Officer .....................102

E. Challenges of Interim Commanding Officers Grouped by Experience and

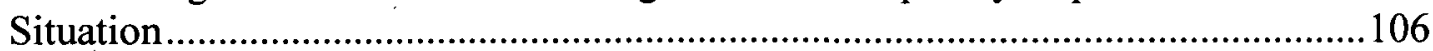

F. Integration of Symptoms and Root Causes ........................................................108

G. Described behaviors of Interim Commanding officers.......................................110

H. Advice for Interim Commanding Officers: .....................................................113 


\section{LIST OF TABLES}

Table 1. Framework of Interim Commanding Officer Experience 100

Table 2. Justifications for Assignment of an Interim Commanding Officer 102

Table 3. Challenges of Interim Commanding Officers Grouped by Experience And Situation

Table 4. Integration of Symptoms and Root Causes

Table 5. Described Behaviors of Interim Commanding Officers

110 


\section{LIST OF FIGURES}

Figure 1. A Grounded Theory Model of Restoring Confidence through Interim

Leadership 


\section{INTRODUCTION}

\section{The Band Didn't Play}

When the commanding officer leaves without a formal ceremony you say, "The band didn't play." Among commanding officers when you utter these words, everyone knows what you mean. You mean it ended badly. The researcher of this study, a Navy officer, witnessed such an event as it unfolded.

I was sitting outdoors in a café, on vacation, prior to heading out to my next assignment as the executive officer of an aviation squadron when the Commodore called me. He said, "There's been a problem." I immediately asked him if there had been a crash, if anyone had been killed. He assured me that there had not been a mishap, but that an investigation was going to begin due to complaints about the command climate. My heart sank. I knew the men in charge of that unit. I'd known them for years and trusted them both. I was slated to step in as executive officer and work directly for the man who was the current executive officer after his assumption of command of the squadron in just over one week's time...

The Commodore delayed my departure until the investigation was over and I finally flew to the unit's location. The change of command ceremony date came and went as we waited to see what would happen. Another week passed and finally the decision came: both the commanding officer and the executive officer would leave. A new commanding officer was on his way to our location. I was to pick him up at the airport the following night. The next morning, behind the commanding officer's closed door, the formal transfer of authority took place 
quietly in front of the Commodore. I was the only witness. The band didn't play. Our squadron now had a new commanding officer, and I was to be his executive officer for an undetermined period of time. I had been there for less than three weeks and barely knew anyone's name. I wondered how the new commanding officer felt! 


\section{CHAPTER 1}

\section{Background to the Study}

This chapter explains the purpose of the study by providing background information about leadership and command in the U. S. Navy, stating the problem that prompted the researcher to undertake the study, and identifying the research questions. A definition of terms is provided at the end of the chapter to familiarize readers with specific naval terminology and usage of the terms within the study.

\section{Commanding Officers in the U.S. Navy}

According to basic military organization, the commanding officer is the leader of the unit who is entrusted with absolute authority, responsibility and accountability. For the purposes of this study, the term commanding officer denotes a naval officer with formal positional authority, as designated by law and military regulation.

\section{Selection for command}

Selection of commanding officers is a formal process. Title 10 of the U.S. Code (1956) outlines the requirements for officers in command. In the U. S. Navy, the selection process is made by a board whose president is a Navy admiral and whose voting members represent the senior leaders in each warfare community, all of whom have previously held command. The service record of each eligible officer is screened and then briefed to the voting officers. A vote of confidence is conducted on the record of each officer. The list of officers selected is reviewed by the president of the board and briefed to the Chief of Naval Personnel. Once approved, the list of prospective commanding officers is forwarded to the community managers who then oversee the assignment of commanding officers, by name, to the units that they will command. Prospective 
commanding officers are usually named about one year in advance of arriving at their units but may be named several years out.

Officers may not be operating within their warfare specialty when they are selected for command. The screening process may occur during a period when officers are working in policy or staff positions, or attending graduate education programs. Based on the scheduled rotation date of the commanding officer who is in place, prospective commanding officers remain at their current assignment until their training track for command begins. This training program includes leadership courses, safety and standardization instruction, platform specific training (surface ship, aircraft, submarine), and other operational and technical training based on the operational warfare specialty of the officer. Upon completion of training, the prospective commanding officer arrives at the unit several weeks prior to the change of command date. In some units, the selected officer steps into the position of executive officer who is second in command of the unit. Assigned as executive officer for 12 to 15 months, this officer is able to refine his leadership skills, become proficient in the operational employment of the unit, and develop a command philosophy and goals prior to the command tour. An off-cycle succession requirement creates the need for a short-term fully-qualified replacement. However, due to the length of the normal command training schedule, a prospective commanding officer may not be immediately available.

There are two fundamental sources for a commanding officer's authority: Title 10 of the U.S. Code, and Navy Regulations. By Title 10 (1956) law, all commanding officers and others in authority in the naval service are required to show in themselves a good example of virtue, honor, patriotism, and 
subordination; to be vigilant in inspecting the conduct of all persons who are placed under their command; to guard against and suppress all dissolute and immoral practices and to correct, according to the laws and regulations of the Navy, all persons who are guilty of them; and to take all necessary and proper measures, under the laws, regulations, and customs of the naval service, to promote and safeguard the morale, the physical well-being, and the general welfare of the officers and enlisted persons under their command or charge. Navy Regulations (1991), in greater detail, describe the responsibility of the commanding officer for his or her command as being "absolute." More specifically, the commanding officer shall, "use all proper means to foster high morale, and to develop and strengthen the moral and spiritual well-being of the personnel under his or her command..."

\section{Detachment for Cause (DFC)}

According to the U. S. Navy's Military Personnel Manual, a commanding officer can be detached for cause (DFC) by his immediate superior for the following reasons: (a) misconduct, (b) unsatisfactory performance involving one or more significant events resulting from gross negligence or complete disregard for duty, (c) unsatisfactory performance of duty over an extended period of time, and (d) loss of confidence in an officer in command. Loss of confidence is a broad classification and is used by a superior officer to describe his or her loss of the special confidence and trust placed in a subordinate commanding officer to achieve the desired level of "morale, good order, and discipline," and the ability of the unit to accomplish its mission (MILPERSMAN, 2002). The phrase "naval commanding officer" evokes the image of a seasoned leader, standing at the helm of a warship, directing the tactical employment of the vessel. 
Ultimate accountability is the hallmark of the office. Recently, however, the U.S. Navy has experienced an alarming trend of commanding officers being fired, with the periodical Navy Times tracking 78 commanding officers relieved in the five-year period from 1999-2004 (McMichael, 2004). In 2004, the Vice Chief of Naval Operations called for a review of the selection criteria for command with the intent of improving the selection process if it was needed; however, the subsequent report did not identify any common themes, and no changes in the selection process were made. In the spring of 2007, Navy Times again documented a string of commanding officers being fired, six in a six-week span (Scutro, 2007).

During the course of operations, when senior Navy officers need to make deliberate leadership changes that are out of cycle with the normal selection and succession process, they will direct a qualified officer to take command of the unit. The action of formally assigning the commanding officer preserves the military chain of command. In many of the cases of rapid leadership changes within Navy units, the officer directed to assume command remained in place for a short period, usually six months or less. In this study, this kind of leader is referred to as an interim commanding officer.

\section{Statement of the Problem}

Senior Navy officers are faced with a problem when evaluating courses of action following loss of confidence in a commanding officer's leadership or commanding officer misconduct. The unique qualifications desired in a commanding officer include leadership ability, familiarity with the organization, tactical expertise, and operational effectiveness. To maintain unit cohesiveness and discipline, the selection of the unit's next commanding officer after a detachment for cause must be made swiftly and 
carefully. Following an unscheduled succession, the prospective commanding officer has likely not yet completed, and indeed might not have yet started, the required training to assume command. If the executive officer is seasoned enough to assume command, that is often the best choice. If, however, the executive officer does not have the desired depth of experience, the gap is normally filled by an available experienced officer, if possible, one who has previously commanded a similar unit. The interim commanding officer will remain in place until the designated replacement has completed required training, can be transferred, and is deemed ready to assume command by the senior Navy officer.

In the U. S. Navy, a command tour is considered the zenith of a career. Command opportunities are highly valued. Officers often describe their first command tour as the most fulfilling assignment that they have ever held. Yet there is no record of how interim commanding officers describe their assignments. Interim commanding officers assume command of units on short notice with no fanfare. They have one known common experience - that of having previously served as a commanding officer. In order to press on with the operational employment of the unit, interim commanding officers subordinate every facet of their lives to keeping the unit on track. They are likely to be separated from their families, removed from their previous duties, and placed in an organization that mourns the departure of its known leader. There exists no body of literature addressing the interim commanding officer, no record of his experiences, no collection point for his best practices or lessons learned.

\section{Purpose of the Study}

This study contributes to the body of literature on unplanned succession and military leadership and was undertaken with three goals in mind. First, the researcher 
sought to better understand the experience of interim commanding officers. By allowing each interim commanding officer to relate his experience through interviews, in his own words, the researcher was able to gain a deep understanding of the lived experience of each officer. Second, through careful examination of the interview transcripts, the researcher documented common experiences and searched for themes that were revealed by the officers as they told their stories. This portion of the study was geared toward providing information to future interim leaders about what to expect upon arrival at the unit and throughout the duration of their assignment, and also to outline possible leadership challenges interim leaders would be likely to face. Finally, this study aimed to provide feedback to senior officials who find themselves in situations causing them to consider assigning an interim leader. By reviewing the perceptions and details presented by actual interim commanding officers about their experiences, senior officers will be in a better position to provide initial direction, continuing oversight, and mentoring to the officers they send to accomplish this task.

\section{Research Questions}

(1) What were the experiences and leadership challenges faced by interim commanding officers?

(2) Which experiences, if any, differed from their first command tour?

(3) What observations were made by interim commanding officers about the organizational culture and morale of the wardroom upon their arrival and departure from the unit? 
(4) Which leadership behaviors and strategies, if any, did interim commanding officers find useful to change the organizational culture and morale of the wardroom?

\section{Explanation of Navy Terminology}

The ships, submarines and aviation squadrons commanded by officers who participated in the study were of varying size. Some were comprised of several hundred personnel while others had over several thousand personnel. Each unit's crew included: enlisted personnel, who perform operations, maintenance, support, and administrative functions; chief petty officers, who act as foremen and subject matter experts; and officers, who make up the management team. In general, ships, submarines and aviation squadrons in the Navy are organized into functional departments (e.g., administration, engineering, deck, maintenance, navigation, operations, weapons and etc.) that are headed by officers who are charged with the formal authority their job title requires. Below the department level are divisions, each having an officer designated to manage the work and lead the sailors who are assigned to that division.

\section{Definition of Terms}

Command triad. The term command triad has developed in the U. S. Navy since the 1980's to define the relationship between the commanding officer, executive officer and the commanding officer's senior enlisted advisor.

Interim commanding officer. Although there is no formal definition of an interim commanding officer, the term is commonly used when referring to a commanding officer who is in command outside of the normal succession hierarchy outlined in Navy Regulations (Chapter 10). The regulations state that for normal succession in cases of 
incapacity or absence of the commanding officer an acting commanding officer, usually the next senior qualified officer in the unit, will assume command. However, in the case of the commanding officer being detached for cause the Navy can assign a qualified officer to assume command until a suitably qualified officer arrives.

Leadership. The term leadership, as it relates to the commanding officer, describes the actions taken by the commanding officer to achieve the goals and mission of the organization. This study focuses on the leadership experiences of officers commanding operational Navy units including ships, squadrons and submarines.

Higher levels of leadership. Naval officers commanding organizations that oversee the unit to which interim commanding officers are assigned will be referred to as higher levels of leadership. These organizations have names specific to a warfighting community; an attack submarine, for example is overseen by a submarine squadron commander, called a Commodore. To simplify the dissertation and to maintain confidentiality, the officer commanding the next higher level of organizational authority will be called the Immediate Superior in Command, abbreviated ISIC, and pronounced Iss-Ick.

Operational unit. This study examined the experiences of commanding officers of operational units: submarines, aviation squadrons and ships, including aircraft carriers. To maintain confidentiality of the participants in this study, the researcher purposefully avoided specifying type of unit commanded or its geographic location, and refers to an operational Navy unit, or simply unit.

Readiness. A unit's operational readiness encompasses its manning (compliment of appropriately qualified personnel), training (achievement of standards required for 
operation of the unit in the performance of its mission), and material status of its equipment (including the physical condition and maintenance of the equipment).

Wardroom. The word wardroom is a standard term in the U. S. Navy to describe both the group of officers within a unit and the room on a ship where officers dine. The term wardroom in this study will be used to refer to the body of officers assigned to the unit who, together, comprise the officer leadership and management team. 


\section{CHAPTER 2}

\section{Review of the Literature \\ Command at Sea}

Command at sea is a term used to describe the scope of responsibility of officers designated with formal authority of command over submarines, ships and operational aviation squadrons. Stavridis and Mack (1999) explained that for command at sea, "...though the size of a ship may be important as a measure of her capability or durability, the smallest minesweeper is equal to the largest aircraft carrier in terms of responsibility and reward." Officers relinquish command reluctantly and usually seek a subsequent command assignment at the next higher level.

I will never forget the excitement of commanding Benfold, of watching it improve every single day. I can't imagine a more rewarding job, and I would have done it for no pay. If I never match it again, I will still be the luckiest man alive, to have had such an experience (Abrashoff, 2002).

This quote from the best seller, It's Your Ship: Management Techniques from the Best Damn Ship in the Navy represents the way commanding officers typically describe their Navy command experiences. They demonstrate an appreciation of having been given the privilege of command- of holding the authority, responsibility and complete accountability of the position. They often speak of the professional and personal rewards that accompany the stewardship of an operational navy unit (Stavridis \& Mack, 1999).

A Navy Times interview of one commanding officer, who took command of a ship 10 months early and then remained in command for over 2 years, revealed that he concentrated on convincing the sailors assigned to the unit that they were part of a great 
unit. He described the sailors as having low morale and feeling victimized because of their association with the ship's bad reputation. He identified low morale as "one of the first things we sought to change" and also assessed that crew members needed to believe in themselves as a unit. He believed his job was to set the tone, delegate responsibility, and hold people accountable (Navy Times, 2004).

Selection for command

When an officer is selected for command at sea, he or she is called a prospective commanding officer and, by Navy instruction, must attend a training syllabus that includes two weeks of command leadership training at the Navy's Command Leadership School in Newport, Rhode Island. During this course, the officer reads current literature on commanding officer roles and responsibilities, leadership, ethics, and teambuilding, and develops a personal vision statement and command philosophy (CLS, 2007). Included in the assigned reading is a Navy study (Leadership, 1985) that described excellence in Navy units. The study outlined the following 12 themes that distinguished commanding officers of superior commands from commanding officers of average commands. "The Superior Commanding Officer (a) targets key issues, (b) gets crew to support command philosophy, (c) develops XO [Executive Officer], (d) staffs to optimize performance, (e) gets out and about, (f) builds esprit de corps, (g) keeps his cool, (h) develops a strong Wardroom, (i) values Chiefs quarters, (j) ensures training is effective, (k) builds positive external relationships, and (l) influences successfully. The commanding officer course is designed for officers to learn and reflect on their upcoming assignments. 
Authority and power

Command in the Navy is a leadership position that is accompanied by formally delegated authority. Pfeffer (1991) discussed the difference between power and authority. When power becomes legitimate, it is authority. Authority has come to be expected and desired in social organizations. In addition to personal power, power may be distributed within an organization by departments or sub-units. "Organizational politics involves those activities taken within organizations to acquire, develop, and use power and other resources to obtain one's preferred outcomes in a situation in which there is uncertainty or dissensus about choices" (Pfeffer, 1991). According to Pfeffer, frequently, within organizations, decisions are made by relying upon standard operating procedures or bureaucratic systems. On other occasions decisions are based on situations and the decision-maker's interpretation of the stream of events. When they are based on politics they are usually characterized by bargaining and compromise and do not reflect organizational goals. The successful commanding officer has the difficult task of learning to become as one with his or her wardroom and crew; yet, at the same time, as leader, remaining above and apart (Stavridis \& Mack, 1999).

The Commander's ability to exercise authority properly is one of most important qualities of leadership (Montor, McNicholas, Ciotti, Hutchinson and Wehmueller, 1998). Proper exercise of authority includes leading by example (Montor, et al.; 1998, Abrashoff, 2002), covenant leadership (Clark, 2000), self-awareness, and emotional selfcontrol (Zaleznik, 1977; Goleman et al. 2002). According to Goleman et al., leaders can become coercive when they use a "do it because I said so" approach, or when they demand immediate compliance without explaining the reasons behind their decisions. 
This authoritarian or command style of leadership can be effective in crisis situations or emergencies but should otherwise be used sparingly especially when directed at people instead of the object of desired change (e.g. the organization's culture or a business crisis). The authors warned that this style is often accompanied by a lack of praise and by excessive criticism and can erode motivation and leave workers feeling alienated. Coercive use of power "undermines a critical tool that all leaders need: the ability to give people the sense that their job fits into a grand, shared mission" (Goleman et al., 2002). One former ship commanding officer asserted that to get the most out of their crews, all Navy leaders deal with the following variables, the leader's needs, the organization's atmosphere, and the crew's potential competence (Abrashoff 2002). In the case of a unit in which the commanding officer was detached for cause, the new leader must subordinate his needs, quickly assess the organizational atmosphere and crew competence, and, with little or no specific preparation, proceed with the business of setting the course. Thus, the unit is subjected to change-a change of leader and therefore leadership style. Depending on the reason for the removal of the previous commanding officer, additional changes in procedures and or personnel might necessarily follow and these changes could affect unit morale, organizational climate, and operational effectiveness. The interim commanding officer must provide leadership to the crew throughout all of these changes.

\section{Leadership}

Rost (1991) defined leadership as an "influence relationship among leaders and followers who intend real changes that reflect their mutual purposes." Although there is not a generally accepted definition of the term leadership, the literature supports the 
notion of leadership as an influence relationship (eg. Conger \& Kanungo, 1987; Schein, 1992). Leader behaviors include setting the vision, aligning followers, inspiring people, motivating followers, and invoking human passion (Zaleznik, 1977; Kotter, 1990). Leadership literature tends to focus on the leader's side of the influence relationship, often listing or recommending effective skills, behaviors and strategies for leaders whereas there is a smaller body of work that focuses on the follower side of the influence relationship.

\section{Charismatic leadership}

Charismatic leaders draw on their exceptional gifts (e.g. personality, heroism, expertise, ideology) as opposed to their positional power to exert extraordinary influence on followers. Conger and Kanungo (1987) proposed that the attribution of charisma to leaders depends on four variables:

(a) the degree of discrepancy between the status quo and the future goal or vision advocated by the leader, (b) the use of innovative and unconventional means for achieving the desired change, (c) a realistic assessment of environmental resources and constraints for bringing about such change, and (d) the nature of articulation and impression management employed to inspire subordinates in the pursuit of the vision.

Charismatic leadership, to the extent that it is ethically applied, is often observed as having a positive effect on followers, particularly when emphasis is placed on shared values within the organization. Cha and Edmondson (2006) found that there are potential negative effects to charismatic leadership in values-driven organizations. The leader articulates values to the employees. The employees interpret and understand the values, 
and in the process, may expand the meaning of the stated values. As the sent meaning and expanded meaning diverge, followers view leader behavior as inconsistent with the stated values of the organization and attribute them with hypocrisy. Followers are then faced with disenchantment, feelings of violation and loss of trust in the leader.

Choi and Dalton (1999) expanded on Conger and Kanungo's (1987) hypothesis that suggested charismatic leaders use self-sacrificial behaviors to build trust with followers in organizations. Choi and Dalton defined self-sacrifice as the "total/partial abandonment, and/or permanent/temporary postponement of personal interests, privileges, or welfare in the (a) division of labor, (b) distribution of rewards, and (c) exercise of power." The authors' research findings confirmed that followers did attribute charisma and legitimacy to self-sacrificial leaders and also found that followers intended to reciprocate the leader's self-sacrificial behaviors. They also tested organizational uncertainty as a moderating variable with leader self-sacrifice and found no significant interaction effects.

\section{Leader and follower relationship}

Hertzberg, in a 1968 Harvard Business Review article on how to motivate employees, proposed a motivation-hygiene theory that differentiated factors contributing to job satisfaction from factors leading to job dissatisfaction. Motivators were found to be: achievement, recognition for achievement, the work itself, responsibility, and growth or advancement. Factors leading to extreme dissatisfaction were identified as extrinsic to the job and included: company policy and administration, supervision, interpersonal relationships, working conditions, salary, status, and security. 
In order to better understand follower compliance, Barbuto (2000) proposed a framework to link leader influence attempts to follower compliance behavior. The author found that:

For each influence trigger, the likelihood of that trigger leading to the target's compliance will depend on the compatibility of the influence trigger with the target's sources of motivation and leader's power bases, in addition to the degree of the target's resistance.

Barbuto's study examined the instantaneous reaction of the follower to the leader's influence behavior and grouped the findings into three categories: power-derived triggers (exchanges, manipulations, role legitimacy, expertise, and leader identification), relations derived triggers (external attribution of follower skills, social identification), and values derived triggers (value approach, internal attribution of follower skills, leader identification, goal identification). Using a five-ringed concentric circle he identified zones of resistance (preference zone, indifference zone, legitimate zone, influence zone, and non-influence zone). Barbuto then posited that followers would be more likely to comply with tasks in their preference, indifference or legitimate zones, but require more inducement when tasks fall into their influence or non-influence zones.

A former U. S. Navy Chief of Naval Operations, Admiral Vern Clark, often used the term covenant leadership to reinforce the idea that seniors and subordinates make commitments to each other. "Leaders promise and commit things to subordinates, and subordinates promise and commit things to the seniors. In our case, our people promise to support the Constitution of the United States. They commit to serve." (Kennedy, 2000). According to Clark, navy leaders are bound by a covenant with the people who serve 
under them to do whatever they can to improve working conditions, maximize benefits, and set an organizational environment that facilitates the achievements of such a committed and patriotic workforce.

\section{Transformation}

Setting the course (figuratively and literally) for a Navy unit is the responsibility of the commanding officer. What to transform and how to go about it are two important questions. In this sense, Burns' (1978) description of transformational leadership applies. The new leader must present a clear and convincing vision of a future that reflects the leader's and the followers' mutual values and purposes, which grow and develop together. Deming (1994) agreed that the "job of the leader is to accomplish transformation of his organization." Quinn (2000) cautioned that, "The process of transformation is bigger than we are. It requires a supportive universe."

Heifitz and Linsky (2002) explained the difference between two types of challenges faced by the organization. The first, technical challenges, are easily addressed by the leader in the role of subject matter expert. The second, adaptive challenges, require real work and learning by the organization. A common pitfall of the new leader is to treat all challenges as technical challenges and personally direct all the measures that need to be used to fix the challenge. In the case of adaptive challenges, the leader, relying on his role as authority figure can actually inhibit the organization from accomplishing the necessary work needed to change. If not permitted to learn new behaviors and develop new processes that support the desired objectives, personnel become dependent on the leader for all responses to challenges and the desired organizational change will fail. 
The literature is confused about defining the terms transformation and change, as they apply to leadership. Transformation can apply to leadership relationships (Burns, 1978), bureaucratic reform (Gore, 1993), processes (Deming, 1994), military organizations (Defense Panel, 1997) and organizational culture (Bossidy \& Charan, 2003).

\section{Organizations and their Cultures}

McGregor (1957) described two approaches for managing employees in organizations. Theory $\mathrm{X}$, a traditional approach, assumed men and women could be motivated by safety needs. Theory $\mathrm{Y}$, a non-traditional approach, assumed that humans naturally want to do a good job and are not resistant to organizational needs, but have become resistant due to negative experiences in organizations. McGregor asserted that if given the opportunity and environment, people would set goals and achieve those goals best by directing their own efforts.

Mintzberg (1979) outlined five basic parts of an organization: three line sectors that include the operating core, middle line, and strategic apex; and two staff sectors that are comprised of technostructure and support staff. The organization's output is generated in the operating core while the direct supervision, management of the organization's boundary conditions and development of the organization's strategy occur at the strategic apex. Administrative and other specialized functions continue to expand the way modern organizations are structured. Using a structural-functional analysis Selznik (1948) listed five imperative qualities organizations must have for maintenance of the system:

(a) the security of the organization as a whole in relation to social forces in its environment, (b) the stability of the lines of authority and communication, (c) the 
stability of informal relations within the organization, (d) the continuity of policy and of the sources of its determination, (e) a homogeneity of outlook with respect to the meaning and role of the organization.

Selznik concluded that no matter how carefully an organization's formal structure is designed, it cannot accurately represent the informal structure that occurs within it. Organizational structures necessarily detail people in their functional roles, a process that does not capture the whole contribution of a person within an organization. Organizations are made up of coalitions or sub-groups of individuals that have differing interests and values, which greatly affect the culture and objectives of the organization (Cyert \& March, 1959). Authority, power and decision-making within organizations are affected by political struggles and social action among and between the organization's sub-groups.

\section{Organizational culture}

Organizational culture is comprised of the beliefs, norms and behaviors within an organization. Schein (1992) explained that organizational culture is seen in the deepest beliefs and assumptions of the members of the organization and can sometimes explain the mysterious and irrational events and influences that surface in the conduct of the organization's business. Schein described three levels of culture: (a) artifacts, which include symbols, language, and overt behavior; (b) values; and (c) basic assumptions, which are taken for granted by an entire group of people. As values are proven to be right over time they become beliefs for the members of the group. "Espoused values" are what members say they believe, but might not be what they really believe.

A newcomer to an organization usually experiences the environment as unique. According to Louis (1980) a process of detection occurs as the person notices changes, 
contrasts, and surprises and then interprets them from a frame of reference that is different from the organizational culture. A formal indoctrination or a sponsor assigned by the organization can help the newcomer assimilate into the organization by providing background information and relevant knowledge. These methods can help reduce confusion for the newcomer and prevent negative feelings during the transition caused by a self-perception that she reacted poorly to surprises in the new environment.

In U. S. Navy units, cross-functional and specialized teams and crews are developed to accomplish operational unit goals. Examples of cross-functional teams include: bridge watch standing teams and emergency response teams. Aircrews and small boat crews are examples of specialized teams. Informal social groups also exist within certain managerial levels in navy units including the Officers Mess called the wardroom, the Chief Petty Officer Mess called the Chiefs Mess or goat locker, and the First Class Petty Officer Association.

\section{Group Cohesiveness}

Group cohesion is a term used to describe the strength of a person's attraction to or identification with the group. Group cohesion is strongly influenced by trust, leadership and team performance (Seibold, 2007; Shen \& Chen, 2007). Social integration in the military is composed of primary group cohesion comprised of peer and leader bonding; and secondary group cohesion comprised of organizational and institutional bonding (Seibold, 2007). Griffith and Vaitkus (1999) made distinctions between peer bonding (horizontal bonding) and leader-subordinate bonding (vertical bonding) and instrumental or task support and affective or emotional support. The authors suggested that a cohesive unit required a positive interrelationship to be present among each of the 
bonding elements and support elements (e.g., horizontal-instrumental, vertical-affective, and etc.). Griffith and Vaitkus also proposed that five components should be considered when examining cohesion in group life: (a) degree or type of stress, (b) group cohesion itself, (c) individual strain, (d) group disintegration, and (e) individual and group performance.

An additional measure of unit cohesiveness in the military is the members' perception of combat readiness. Shamir, Brainin, Zakay, and Popper (2000) asserted that, "collective efficacy beliefs reflect not only the abilities, skills, and knowledge of unit members, but also the characteristics of the unit, including its leadership." In their study on perceived combat readiness as collective efficacy, the authors found only a modest correlation between aggregated soldiers' perceptions of combat readiness and aggregated staff members' perceptions of combat readiness indicating that each group was influenced by a different set of factors in their assessments. However, "for both staff members and soldiers, the stability of leader-unit relationships (the leader's tenure in the unit and the mean length of soldiers' service in the unit combined) was positively related to perceived combat readiness..." A second notable finding of this study was, "... a strong relationship between identification with the unit and perceptions of combat readiness." The authors posited that leaders could focus attention on utilizing symbols and slogans, emphasizing shared values, and engaging in inclusive behaviors to positively influence members' identification with the unit.

\section{Leading Planned Change}

A seemingly endless stream of bestsellers can be found on the subject of leading change in organizations. A long list of new titles is scheduled for publishing every year. 
Many of the authors present a formula for success to leaders of change in organizations. Conversely, the authors also outline common faults organizations encounter when attempting to implement organizational or cultural change. Two bestsellers, The Heart of Change (Kotter, 2002) and Good to Great (Collins, 2001) examine success in large corporations subsequent to organizational change. Both authors concluded that corporate success was rare compared to failure, and that most people do not adapt well to change. Kotter, beginning with, Leading Change (1996), and following up with What Leaders Really Do (1999), and The Heart of Change (2002), used an eight step model to present the lessons he derived from his study of over 100 organizations: (a) increase urgency, (b) build the guiding team, (c) get the vision right, (d) communicate for buy-in, (e) empower action, (f) create short-term wins, (g) don't let up, and (h) make change stick. Kotter's enduring eight-step framework provides an excellent structural tool to examine literature related to leading change in organizations.

According to Kotter (2002), a feeling of urgency about change is most likely to occur in an organization when the people in that organization have a reaction to what they see currently happening. Kanter (2004) asserted that when an organization has been assessed as being in a losing streak, "the situation is always worse than anyone thinks." People do not react with urgency to analyses or reports presented by management, but are more likely to embrace change after seeing a representation of the current reality within the organization, which causes them to feel like change is needed. Kotter is clear on this process: people first see, then feel, then act. Even when analysis reveals the need for change, people resist until they develop a feeling that change is needed through the seefeel-act process. Collins (2001) called this, "Confronting the brutal reality." He asserted, 
"Yes, leadership is about Vision. But it is equally about creating a climate where the truth is heard and the brutal facts confronted." Most of the literature supports leadership developing measures that contribute to cultural change as a part of achieving organizational change, but Kotter is one of the few who holds that it is the essential first step.

Kotter's second step is, "building the guiding team." He describes the team as having the "the appropriate skills, the leadership capacity, the organizational credibility, and the connections to handle a specific kind of organizational change." Throughout the 1990s, corporate America exhibited an operational paradigm where corporations sought to create success in businesses through the hiring of outside leaders who had a proven record of success. The current navy system of choosing an interim commanding officer based on past performance in a similar organization adheres to this philosophy. Collins (2001) asserted that the first essential step to improving a company is picking the right leader and then picking the right team. In a five-year study examining 28 corporations that beat their competition in the stock market an average of seven times in 15 years, Collins discovered that a common theme was concentrating on "first who, then what." This contradicted the researchers' assumption that winning corporations would first develop a vision and strategy and then seek the leadership team. In fact, it wasn't until the right people were on board that they were able to develop the strategy that eventually propelled the companies into their position of success. Nadler (1999) after interviewing Henry Schacht, a change agent and the first CEO of Lucent Technologies, identified the change leader as a "heroic leader" whose role in the corporation was, "envisioning, energizing and enabling." Collins (2001) discovered, however, that "larger-than-life, 
celebrity leaders who ride in from the outside are negatively correlated with taking a company from good to great." Success was often noted in the short term, but corporations that had recruited a heroic leader failed to sustain the success over time.

Collins (2001) detailed a finding of "level 5 leadership" in executives of good to great companies. The "level 5 executive builds enduring greatness through a paradoxical blend of personal humility and professional will." Collins compared level 5 leadership to the "level 4 leadership" of an "effective leader who catalyzes commitment to and vigorous pursuit of a clear and compelling vision, stimulating higher performance standards," commonly found in good corporations. Bossidy and Charan (2002) listed seven essential leadership behaviors for getting things done: (a) know your people and your business, (b) insist on realism, (c) set clear goals and priorities, (d) follow through, (e) reward the doers, (f) expand people's capabilities, and (g) know yourself. For corporations experiencing successful change, the literature is undecided. Some researchers identify a leader who is quiet and humble, others describe a dynamic change agent whose personality drives the organization's strategic vision and goals.

Kotter's third step, "getting the vision right" is well supported in the literature; however, the literature is divided on whether the leader's vision applies to the strategic direction for the corporation or the internal development of the organization. Throughout the 1990s, the U. S. Navy embraced Total Quality Management practices (Deming, 1990) and units were committed to establishing an Executive Steering Committee to develop the organization's mission, vision and guiding principles. Covey (1990), advocated the benefits of setting a mission statement that is meaningful and reflected the values of all members of the organization. Lippitt (1998) warned that there will be resistance when the 
decision-making and development of the vision are made by a small homogeneous group at the top of the organization. In a related observation, Collins (2001), asserted that developing a list of what not to do was often equally as important as developing a vision of what to do. Senge (1990) identified the leader as one whose vision includes design of the organization as a whole. Senge's emphasis on developing a "learning organization" can be classified as a developing a shared vision for the organization, but, also as a cultural change.

There is uniform consensus about the importance of communication and buy-in during the change process. Kotter's fourth step, "communicate for buy-in" described a need for "simple heartfelt messages" designed to impact the listener at the gut-level. Stories that are credible and relate to real events are most effective. In a well-written handbook entitled, Generating Buy-In, Walton (2004), promoted a three-step framework for strategically designing stories that target peoples' vision and commitment to the future. The leader first determines what action is desired from the audience, then (a) establishes the strategic storyline, (b) develops the storyline in three "chapters" that describe how followers will be fulfilled and (c) calls the audience to action. Speeches using frameworks such as this one are commonly used in political addresses to generate support for the leader's positive vision for the future as they move the audience away from concentrating on the problems of the past. Walton asserts that the positive impact of the message also "empowers the person who delivers it." Collins (2001) did not identify buy-in specifically as an essential element of corporate transformation; instead he advocated that creating a climate in which the truth can be spoken and heard is an important factor in "confronting the brutal reality." 
Kotter recommended, as a fifth step, to "empower action" by removing barriers. In recent literature, authors frequently used the terms hardware and software when describing what to target to affect cultural change in organizations. The vision is commonly seen as a design to change the software, or the thinking of members of the organization. The hardware refers to the systems and processes existing within the organization that must also be changed since old methods and practices often reinforce old behaviors and beliefs. Organizational culture change can be thought of in three ways according to Trice and Beyer (1993), (a) revolutionary and comprehensive, (b) subunit or subculture, and (c) cumulative comprehensive reshaping. Change on any level causes friction and tension in organizations as some members agree, embrace or reject the notion of change. Martin (2006) asserted that people can perceive change as a threat to their environment and the magnitude of change is related to a person's perception of a loss of control over their immediate environment. For any level of change, it is imperative that leaders are first aware of the actual existing culture and second, anticipate resistance to efforts to lead change.

Trice and Beyer identified various causes of resistance to change at the individual level: fear of the unknown, self-interest, selective attention and retention, habit, dependence, and need for security; and sources at the group level: threats to power and influence, lack of trust, different perceptions and goals, social disruption, resource limitations, fixed investments and inter-organizational agreements.

Sull (2002) described the organization's persistence in acting with established behavior patterns as "active inertia." When studying companies that had failed to take appropriate action when business conditions changed, the author discovered that 
companies failed to move away from the strategies that previously brought them success. Kegan and Lahey (2002) found that people may have "competing commitments" to the new vision and culture desired to achieve change. By investigating what each person holds as their underlying assumptions, the basis for a single person's resistance to change can be revealed. In a case study on organizational restructuring over a five-year period, Gavin (2003) described a powerful sense of loss felt by the members of the organization. Her analysis, based on psychoanalytic theory compared the loss of the leader to the loss of the father figure. A period of profound loss accompanied by resistance to change during the mourning period ensues. Manifestations of the experience of loss included frequent references to the past as a better time, hostility toward the new leader, fear, uncertainty and at its extreme, chaos.

Navy units are typically close-knit with a personnel base that is extremely loyal to their commander, around which is created a strong unit identity. Levy (2001) asserted that high performing teams who operate autonomously and have a strong identity are often resistant to change. Further, such teams are likely to develop their own rules and are reluctant to disclose poor performance. Leaders might tend to overlook the avoidance of such high performing teams to buy-in to the new strategy because of the team's autonomy and operational success. This cycle creates a barrier to cultural change.

The literature reveals that change is seen as threatening; singly by leaders, collectively by organizations, and individually by employees. Leaders assess the organization's tolerance for change in the current environment and their energy to sustain transformation efforts as limited. Leaders become fatigued by internal organizational change particularly if the external business environment is also turbulent. Heifitz and 
Linsky (2002) remarked that "the deeper the change and the greater the amount of new learning required, the more resistance there will be and, thus, the greater the danger to those who lead."

Kotter's advice for the sixth step in leading change is creating short term wins. Taking the time to recognize and celebrate the victories is viewed as important in the literature. Meyerson (2002) recommended, "picking the low hanging fruit," a practice of intentionally creating a strategy that targets low cost, short term results. Creating shortterm wins also help to maintain the momentum of change and reinforces the strategic story that is told by the leader, which embodies his or her vision. A drawback of this recommendation is the restraint the leader must use to prioritize the work of transformation. As the leader sets the agenda, the leader must be careful not to undertake the biggest and most important element first, particularly when the results will not be realized until far in the future. The organization will become tired of promises of success without seeing some results. The leader must be attuned to the organization's climate to determine when a new practice or result will be appreciated as a win and how to reveal or celebrate it. Hollow reports of victory will be exposed as the leader manipulating the data to demonstrate a success when there isn't actually one.

Persistence is Kotter's seventh step. He advised the leader, "Don't let up." For Kotter, this step is linked to step one, increasing urgency by continuing to "show 'em, show 'em, show 'em." Showing them reiterates his previous point that people need to first see, and by seeing develop an emotional response that motivates change. To this end, the leader must display motivation and faith throughout the change process. Heifitz and Linsky described a process in which the leader "controls the heat" or tension created by 
change. He or she "orchestrates the conflict" within the group's limit of tolerance for discomfort caused by change.

Change agents are used in organizations to develop and implement strategic change. Change agents can be external to the organization as in the case of a hired consultant, or internal, such as a designated leadership or management position or team within the organizational structure (Caldwell, 2003). In some cases, an organization's turnaround begins with a change in the top leadership position (Kanter, 2004). The literature supports replacing the top leader in cases where a symbolic effect is desired. The action of replacing the top leader is significant to the organization internally because the new leader is not associated with previous failures, carries the credibility of his past successes, and is disassociated with the cultural or systemic dynamics that may perpetuate the root causes of the organization's dysfunction (Ginsberg and Abrahamson, 1991; Johnson, 1990; Kanter, 2004). Kanter (2004) also asserted that replacing the top people in an organization subsequent to a losing streak is often a first step in restoring external confidence.

There is strong support in the literature for the last step of Kotter's framework, making change stick by using metrics and by tying performance evaluations to the new business practices or desired elements of organizational culture. Creating the right metrics to assess progress is difficult but essential. The organization may have to change its current standards of determining success. Measuring the organization's progress toward achieving elements of the desired culture can be done by survey within the organization. Collins (2001) determined that business practices within the organization must be constructed to require desired behaviors as an element of success. Over time, the 
organizational culture will shift and build around the behaviors that are tied to success. The result will be a changed culture. This process is supported by Bossidy and Charan (2002), who found that telling people the desired result and structuring the system to reward members for producing said result causes change to occur. Kotter asserts that the culture cannot be changed first. The culture is the last thing to actually change.

\section{Summiary}

This literature review has revealed the complexity of the task facing any leader arriving during a period of leadership transition or desiring to effect change within an organization. Examining interim commanding officers' experiences within a military culture of unit loyalty, military discipline, and operational autonomy will contribute to the body of literature focusing on leadership behaviors, organizational culture change strategies, and frameworks for leading change. 


\section{CHAPTER 3}

\section{Research Design and Methodology}

\section{Qualitative Methodology}

The purpose of this study was to understand the experience of interim commanding officers and to examine their perceptions of the leadership challenges that they faced, the skills and behaviors that they found to be helpful to them, and their assessments of the impact of an unscheduled leadership change on the organizational climate of the wardroom. A qualitative research methodology was especially appropriate for this study because it brought to light the experiences of a specific subset of experienced commanding officers who have faced a unique succession experience. By capturing the personal experiences of a selected sample of this small group, this study will begin to build a body of descriptive literature addressing this phenomenon.

Qualitative research is based on the notion that "human behavior is always bound to the context in which it occurs" (Ary, Jacobs \& Razavieh, 1996). The ultimate goal of qualitative inquiry is to gain a deep and full understanding of human experience within a specific reference. The researcher was, therefore, committed to examining events and experiences from the participants' points of view and collecting sufficient detailed data to document what it means to be an interim commanding officer. The researcher also undertook the research project with the goal of providing helpful information to future interim commanding officers and senior naval officers about this kind of assignment.

Qualitative research is conducted to achieve a complex detailed understanding of an issue (Creswell, 2007). Corbin and Strauss (2008) explained, that: 
any explanation of experience would be incomplete without (a) locating experiences within the larger conditional frame or context in which it is embedded; and (b) describing the process of the ongoing and changing forms of action/interaction/emotions that are taken in responses to events and the problems that arise to inhibit action/interaction. (p. 17)

Often, the design of a qualitative study is not set rigidly, but allowed to emerge as the data is revealed by the participants. Prior to conducting this study, the researcher was able to observe the entire duration of an interim commanding officer's six-month assignment. To understand the experience from the points of view of the participants, it was all the more important for the researcher to probe deeply into her existing assumptions and beliefs and suspend them during the design and throughout the duration of the study. She was influenced by phenomenology, in which the researcher's ability to control her subjectivity is emphasized and explained in detail. To understand the context, the researcher was influenced by case study design, using cross case analysis and vignettes to identify critical moments within the storyline of the interim commanding officer's experiences. A case study design was not possible for this study due to the necessity of preserving the confidentiality of the participants. This study used Grounded Theory Method to provide the best means of collecting, understanding, analyzing and displaying the data. Utilizing the constant comparative method described by Strauss (1987) and Strauss and Corbin (1998), the researcher developed theories about the causal conditions, actions and interactions, and outcomes grounded in the views of the participants (Creswell, 2007). 
In this study, the participant and the researcher both engaged in the process of examining the events, as described by the participants, to more fully understand the experience from the participant's point of view. Fossey, Harvey, McDermott and Davidson (2002) asserted that good qualitative research illuminates "the research participants' subjective meanings, actions and social contexts, as understood by them." The researcher's subjectivity must thus be controlled. The literature suggests that researcher bias must be recorded, examined, and addressed within the study (e.g., Wertz, 2005; Morrow, 2005; and Giorgi, 1997). Reflexivity refers to the self-awareness of the researcher. Morrow (2005) offered several ways to achieve reflexivity including: keeping a self-reflective journal, consulting with a research team, peer debriefers, or focus group, and engaging in participant checks (consulting with the participant to confirm that the researcher's interpretation mirrors the participant's experience.) The researcher utilized three methods to control her subjectivity while conducting this study. Prior to the first interview, the researcher wrote a memo about her experience in a Navy unit under the leadership of an interim commanding officer to document her existing assumptions. During the study she kept a self reflective journal. The researcher discussed researcher bias with a knowledgeable colleague using these two documents as a basis for identifying her assumptions and pre-existing beliefs. During each interview, the researcher conducted participant checks to ensure the accuracy of the documentation and understanding of the participant's narrative. 


\section{Method}

\section{Collection of Data}

Selection of the number of participants in qualitative research is less precise than in a quantitative study and is not necessarily decided in advance. The literature suggested that for descriptive qualitative research, the researcher interview sufficient participants to achieve a point of redundancy or saturation in the information. Grounded Theory Method, as explained by Corbin \& Strauss (2008), suggested the utilization of theoretical sampling during which the researcher engages in an ongoing development of concepts during the data collection phase. Keeping in mind the emerging concepts, the researcher examines and refines those concepts under a variety of conditions. Data collection is terminated when information about the concepts is saturated.

From open source media, the researcher compiled a list of units in which an unscheduled succession event had occurred between 2000 and 2007 and identified the follow-on commanding officers who fit the study criteria: (a) when selected, they were not in training for command, (b) the duration of their command was shorter than a normal command tour, and (c) they previously held command of a similar unit. Purposeful sampling was used to increase the variety of experiences across the different types of operational Navy units (e.g., submarines, ships, and squadrons). It is important to note that all cases listed male officers as the follow-on commanding officer. Therefore, all of the possible participants were men. People fitting the selection criteria were contacted by phone or by e-mail by the researcher to ask if they would be willing to participate.

Eleven men, ranging in age from 43 to 51 , volunteered to participate in the study without payment. All participants had served as interim commanding officers in the 
United States Navy between the years 2000 through 2007. During this period, the highest uniformed leaders of the United States Navy publicly expressed concern about the number of commanding officers that were fired. Six of the participants currently served in the United States Navy and five of the participants had retired from naval service. One participant did not meet all criteria of the study. He was originally notified that he would be an interim commanding officer, but one week after taking command of the unit he was informed he would stay for a full tour of duty. The participant was included in the study. His interview was examined to determine if there were similarities between his experience and the experiences of the other participants and at which point or points in the story he told the deviations occurred.

During the first contact with a participant, the researcher explained how she selected his name from open source media. She offered each person a copy of the proposal abstract, detailed the expected duration of the interview, and explained that a consent form would be used. Copies of the dissertation proposal abstract, the research participant consent form (Appendix A) and the interviewer's guide (Appendix B) were subsequently forwarded to each participant via e-mail. The second contact between researcher and potential participants was by phone or e-mail and included answering questions about the study and reviewing the consent form. Of note, all of the men who were contacted enthusiastically agreed to participate in the study making themselves available for interviews either in person or by telephone within a week of first contact.

Participants acknowledged receipt of the dissertation proposal abstract, participants consent form, and the framework for the interview questions. The consent form was completed and returned prior to each interview. Participants were encouraged 
to avoid analytical narratives and concentrate instead on their actual state of mind during the events, describing their feelings, and perceptions as the experience unfolded. Participants were informed that the interviews would be conducted in the form of a dialogue about their experiences as interim commanding officers. Participants might have initially felt uncomfortable about the possibility of being asked how they felt throughout their tour as interim commanding officers because their sense of duty in accomplishing the task would have led them to believe that their feelings were irrelevant. The researcher, drawing from the phenomenological tradition explained the goal of her qualitative research as seeking to fully understand a human experience. In that way, the researcher helped to alleviate any stress that would arise from participants revealing their personal feelings and perceptions. Additionally, participants might have been reluctant to engage in a free-form discussion if they believed that the research was designed to judge the previous commanding officer, assess the senior official's decision to assign them as interim commanding officer, or analyze their success in performing this function. These concerns were addressed prior to the interview with reassurances that these topics were not the focus of this study.

Five face to face interviews were conducted. An additional six interviews were accomplished by phone due to the geographic location of the participants. All interviews were recorded on audio cassette with the participants' permission. Some interviews were transcribed by the researcher while others were transcribed by a trained transcriber who signed a confidentiality agreement. Transcribed interviews were then examined by the researcher for accuracy of naval terminology. Corrections were made as needed. Finally, the researcher sanitized the transcribed interviews removing any details including names, 
geographic locations, and events that would compromise the confidentiality of the participants.

Each participant was interviewed for approximately one hour, utilizing openended historical prompts, for example, "Tell me about your experience as an interim commanding officer." Unstructured interviews allowed the researcher to gain insight into the broad existential aspects of the participants' experiences (e.g., spatiality, corporeality, relationality, and temporality) by allowing them to explore their memories of experiences using their own words and organization. Open-ended questions and experience questions were used to the maximum extent possible to facilitate the greatest deal of expression in their own words by the participants. Beginning with the fifth interview, the researcher, upon concluding the open-ended questions, began including a discussion of the emerging concepts with the participants. The researcher was careful to maintain confidentiality, focusing on the concepts and not revealing specific cases or people. These discussions provided valuable refinement and synthesis of the concepts and themes of this study and improved the internal validity of the study.

Two follow-up interviews were conducted to clarify statements and probe for further information in order to be able to answer the research questions. During the original interviews and during follow-up interviews, the researcher used member checks and descriptive or structural questions to confirm understanding of the participant's statements. Prior to a follow-up interview, the participant had an opportunity to read a transcript of the first interview and engage in a process of reflection. The follow up interviews, conducted by phone, were conducted as a dialogue in which both the researcher and the participant considered and interpreted the preliminary themes drafted 
by the researcher. During these conversations, participants assisted the researcher in relating the meaning of their experiences to the research questions.

In this study, the first two research questions look for common themes in the interim command experience and how that experience might have differed from the first command experience. Since each interim commanding officer previously commanded a unit and went through a common selection process, the researcher used the first openended question to understand generally how they experienced their assignment as an interim commanding officer. As part of the interviewing process, the researcher asked additional questions seeking to reveal the perceptions of interim commanding officers about the command climate particularly as it related to the officers in the wardroom. These questions were geared toward providing data to respond to research questions three and four. The researcher continued to use open-ended prompts such as, "Tell me about meeting with the wardroom." Depending on the depth of the response, follow-up questions were asked to clarify the experience, for example, "What were your feelings as you prepared to meet the members of the wardroom?" Or, "After meeting with them, what were your perceptions about the wardroom?" The researcher avoided unintentionally influencing the participants by asking questions that reflected the researcher's assumptions and biases, such as, "can you describe an instance where you were concerned about the morale or cohesiveness of the wardroom?" This type of question offers the participant themes to use in interpreting their feelings, experiences, and observations without allowing them to reflect and identify what they actually felt, experienced, and observed. 
Analysis of Data

Data analysis began after each interview and continued after the interviews were transcribed. The researcher engaged in a period of in-depth reading and reflecting on the actual words used by the participants to describe their experiences. Morrow (2005) described this technique of "repeated readings of transcripts, listening to tapes, and review of field notes and other data," immersion in the data. The researcher began writing memos to document the themes that emerged from each interview. The researcher's first interpretation of an interview was sent by email to the participant with a copy of the participant's transcribed interview to verify that the researcher had accurately captured the themes within the interview.

Once the researcher was immersed in the data and felt comfortable that she understood and could accurately document the experiences of the interim commanding officers and the challenges they faced, she began data analysis using the Grounded Theory Method to address the third and fourth research questions and to develop a framework for presenting the findings. According to Strauss (1987), the goal of grounded theory is "to generate a theory that accounts for a pattern of behavior which is relevant and problematic for those involved."

The transcribed interviews were subjected to open, axial and selective coding (Corbin, 2007, Strauss \& Corbin, 1998, Walker \& Myrick, 2006) using qualitative data software called MAXqda. The software program organized the codes and coding system and facilitated the constant comparative method. The use of this program gave the researcher a great deal of flexibility in coding and sorting data and organizing memos. The researcher first engaged in open coding. She examined each interview line by line 
and wrote a memo capturing themes and questions. As themes emerged memos were generated to capture the researcher's realizations and additional questions about the themes.

Next, using axial coding, themes were compared to each other, to sub themes, and to the literature establishing relationships between the themes (Strauss, 1987). Using Strauss and Corbin's specific approach to grounded theory, the researcher focused on identifying conditions, actions/interactions, and consequences. Finally, selective coding was conducted. A core category was selected from among the themes. The core category in this study was restoring confidence. During selective coding the themes were integrated and refined using the core category. In this phase, the researcher looked for consistency in the theory developed and tested theories against the raw data to identify disconfirming data and negative cases. The theories ware then translated into the language of the leadership discipline and presented as hypotheses to guide future studies. Many devices can be used by researchers to organize and represent the data including: tables, figures, diagrams, photographs, frameworks, lists, and spreadsheets. To understand the meaning and relationships between categories of data, themes and subthemes, tables were used for data presentation in this study and placed in Appendices to the text.

It was a goal of the researcher in conducting this study to adhere to rigorous standards of credibility and dependability. In qualitative research, credibility and dependability equate to internal validity and reliability, the methods commonly used to measure quality in quantitative research. The researcher sought to enhance credibility of this study by clarifying researcher bias, and by using researcher reflexivity, rigorous data 
analysis and participant checks (Cho and Trent, 2006, Creswell, 2007)). The goal of the research design, transparency of the process of data collection and analysis, and presentation of the findings was to demonstrate dependability.

\section{Delimitations and Limitations}

This study examined the experiences of a very small group. The members do not constitute a large enough sample of operational commanding officers to assert that their perceptions or experiences in their first command tours or interim command tours could be generalized to a larger population. Data about the commanding officers was collected and analyzed solely to provide a basis for comparison between their first experience as a commanding officer and the experience of being an interim commanding officer.

The study was designed to enable a dialogue between the researcher and the participant that was based on honesty and a deep understanding of the participants' experiences. The study was limited by the skill of the researcher and the willingness and ability of the participants to provide depth of detail about their experiences.

Stereotypically, one might not have believed that a military officer would fully cooperate in this type of study. However, there has recently been a strong move to formally educate naval officers about leadership and self-awareness during the command leadership course, which might have made the participants more willing to contribute on a deeper level.

The researcher does have experience as a squadron commanding officer and has had an opportunity to observe an interim commanding officer during the duration of his assignment. This study was limited by her skill in setting aside preconceived ideas about 
those experiences and any personal biases or internal frameworks that could have clouded her ability to be objective.

\section{Significance of the Study}

The enthusiasm expressed by the participants upon receiving the invitation to participate in the study and during the interviews increased the researcher's perception that the story of what it means to be an interim commanding officer needed to be detailed within the study. Therefore, in the development of this research design, the researcher sought to understand the experience of interim commanding officers within their individual contexts. The researcher was very conscious of maintaining her subjectivity and conducting participant checks to ensure accuracy of the data. Interviews were read and re-read to pull out themes and key statements. The themes and key statements were then interpreted for their meanings. Once the researcher fully understood the experience of the participants, she progressed to Grounded Theory Method. The study should assist future interim commanding officers by providing actual data to familiarize themselves with possible challenges and pitfalls they may face. It could also offer objective findings to senior Navy officers to guide their actions during selection and oversight of interim commanding officers. 


\section{CHAPTER 4}

\section{Research Findings}

\section{Introduction}

This study is an initial foray into understanding the experiences of interim commanding officers in operational Navy units. A systematic analysis of the interviews revealed rich data and contextual information about the individual experiences of the participants. Saturation of the data in several areas allowed the researcher to recognize and link emerging concepts to begin the process of developing theories about the interrelationship of the concepts. This chapter describes the experiences of the participants, reports on how the interim commanding officer experience differed from their first commanding officer experience, details challenges commonly faced by interim commanding officers and strategies and behaviors they found useful for countering those challenges, identifies and integrates themes that emerged from the data, and presents a grounded theory model representing the motivations of the interim commanding officers and the actions, interactions and outcomes that were revealed in the data.

\section{The Experience of Being an Interim Commanding Officer}

A review of the stories told by 11 Participants revealed a common series of experiences occurring during the timeline of their tours as interim commanding officers. A table used to sort and interpret the experiences is located in Appendix C. The experiences were grouped by the researcher into three categories: (a) arrival, which was comprised of awareness of the event and notification, preparation, and incoming change of command; (b) interim command leadership, which included immediate actions, assessment and identification of priorities and focus areas, and promotion of cycles of 
transformation; and (c) departure, which incorporated the outgoing change of command, and internalization of the event. The researcher used categories to present findings that are representative of an interim commanding officer's tour of duty. It was interesting to note that one of the participants included in the study was assigned as an interim commanding officer, but one week after arriving at the unit he was informed that he would stay for the duration of a full tour. This participant's experience was similar to the other participants through the arrival category. However, the participant's discussion of the events after learning of the extension did not mirror the other interviews. Additionally, this participant assumed command of a unit from which the previous commanding officer had been relieved for a reason related to his personal conduct. The reasons were not known by the crew and the participant mentioned that he was only concerned with the effects of the incident on one officer within the crew. The researcher chose to include this interview in the study for the purpose of learning which of his experiences were similar to the other participants' experiences and to examine a case in which the removal of the commanding officer had minimal effect on the crew.

Arrival

In the arrival phase, the participant learned of the incident, was notified that he would become the interim commanding officer, made what preparations he could for the assignment, traveled to and took command of the unit. The timeframe between the participants' notification that they were to become the interim commanding officer and taking command varied from 1 hour and 15 minutes to several weeks (including travel time and recertification time.) In only two cases, the participants were already assigned to the same United States homeport as the interim unit and took command of the unit at that 
homeport location. In two other cases, the participants were already assigned in the same overseas homeport location of the interim unit and took command in that overseas homeport. Seven of the 11 participants were required to travel to meet and take command of their interim unit in distant ports, and most of those ports were located geographically outside of the continental United States.

Operational command requires certain qualifications and competencies from commanding officers, particularly in the aviation and submarine communities because the commanding officer is expected to have their qualifications current to operate the specific type of aircraft or to be certified to operate the ship's reactor. Some participants described how they knew they were on "the short list" to be called because of the currency of their qualifications or the lack of availability of other qualified officers. Two received unofficial calls from their personnel managers alerting them that they were being considered for the assignment to give them a longer lead time to prepare for the assignment and travel. Two participants recalled proactively contacting the decision makers to volunteer for the assignments or to remove concerns about possible effects on their time ashore or impact on their families that would exclude them from consideration. Two participants had previously commanded operational units in the Navy, but had not been screened by a Navy selection board for the specific level of command required for the job. All participants recalled feeling confident that their experience would allow them to succeed in the position of interim commanding officer.

Awareness of the incident and notification. Interim commanding officers initially heard about the incident that would cause the removal of the commanding officers that preceded them in a variety of ways. One participant described hearing about the incident 
on $\mathrm{CNN}$, while on leave. Two received direct phone calls from decision makers in the units' chains of command stating that the chain of command was considering removing the commanding officer and asking how soon the participant could be there to take the assignment. Others described having heard rumors of the impending removal of the commanding officer through the grapevine. Six of the 11 participants were assigned to the staff at the unit's next level of command. (Warfighting communities have different names for the next level of command, for submarines it is the squadron commander, for aviation it is a wing commander, etc.). For the purpose of maintaining confidentiality in this study, the next higher level of command will be referred to simply as the Immediate Superior in Command (ISIC). In three cases, the participants were assigned to the ISIC staffs and described having been personally involved in helping the commanding officer to find solutions to problems that the participants had previously observed about the unit from their level of supervision.

Many of the participants described the commanding officer that was relieved as a friend, a good friend, or in some cases, a Naval Academy classmate. There were few cases where the participant did not know the commanding officer he would be relieving. Participants related that their awareness of the incident or decision to remove the commanding officer was often accompanied by feelings of disappointment and sadness for the current commanding officer. However, they immediately began an assessment of their own place on the list of possible replacements. In one instance, a participant described his surprise at still feeling tension about the disappointment and anger he had: [It was] about the fact that I expected that these successful people who had successful careers, and [were] placed in command to be able to take care of this 
treasured asset, this nations' asset, the ship and the crew, and to move them on, and lead them in a good direction. And [he] had certainly failed in this particular area. The injustice of that just makes me angry.

For other participants, the sadness and disappointment were also related to their personal investment in the career development or success of the commanding officer and crew over the preceding months or in previous tours of duty. Several, who worked on the staffs of the ISIC, described feelings of personal failure in being unable to turn around the series of events that led to the removal of the commanding officer. It was a common reaction for the participants to predict the removal of the commanding officer based on details released publicly or information that was shared by friends and acquaintances from their experience in their warfighting community (type of ship, submarine or aircraft). This necessarily led to an assessment of the possibility of being considered as the replacement. As one participant stated, "So there were a lot of variables, I didn't know for sure if I would be the guy, but I realized that I was definitely, probably on the short list." There were only two participants who, after hearing of the incident or events, either didn't believe the commanding officer would be relieved or didn't believe they would be considered for the assignment.

Most participants, who were serving on staffs of the ISIC, were informed of their selection by the ISIC himself, however several were informed that they were being considered for the assignment and then selected by a higher operational commander. Of the participants who were not on the staff of the ISIC, most were called by the Chief of Staff or Deputy of the ISIC and informed that they had been chosen to take command. Those participants who received advance knowledge about the assignment expressed 
either neutral or positive reactions to the information. Receipt of the information prompted them to contact the decision maker to express their willingness to take on the challenge or they used the information to begin thinking about the assignment and what they would do if selected, as shown in the following example:

And so my [personnel manager] gave me a heads up and he said, "this is probably what's going to happen. The investigation is going to take a little while, and then somebody's going to call you on a Friday afternoon and tell you to get on the flight and go to [overseas port] and take command of the ship." He said, "Don't say you heard it from me, but that's what's probably going to happen." So he gave me a little bit of a heads up and helped to make sure I was thinking about what I would do if I were to go over there. And it turned out the Friday after [holiday], [the ISIC] called me up and said, "Get on the ship. Get on a plane, fly to [overseas port] and take command."

Participants described experiencing conflicting emotions about becoming interim commanding officers. They felt sadness for circumstances at the unit and the situation of the unit's commanding officer but excitement about the possibility of commanding again. The excitement was amplified by feelings of certainty that they could succeed in the situation and confidence in their ability to command. Most described feeling honored at being considered for the position and after being selected, they felt they had been given a gift, the gift of being able to command again.

Preparation. None of the Interim Commanding Officers interviewed described developing a comprehensive plan prior to arriving at the unit. Those who had lengthy travel to the unit's location did engage in reflection or sorting through their thoughts, 
occasionally making notes or lists during the plane ride about concerns they had, programs they wanted to be sure to assess, or people with whom they needed to meet. One participant described a feeling of embarrassment as he related that he had arrived at the unit without a plan or goals. However, all participants expressed having confidence in their ability to make an assessment upon arrival and, relying on their judgment and experience amassed throughout their careers, select the correct priorities and focus areas to best suit the situation they would encounter.

Participants' preparations were limited by the time between notification and travel. Most participants communicated with the unit's administrative ISIC and when able and applicable, the unit's operational commander. In cases where there was an incident causing death or serious injury to a crewmember or extensive material damage to the unit or when there was a perception of heightened public interest in the incident, there seemed to be a greater level of interest by higher levels of operational and administrative command. Within the cases examined, participants who took command of submarines and aircraft carriers described a greater level of interest by higher leaders in the Navy in their selection as interim commanding officers and recalled being given more guidance by higher leaders and their staffs during their preparation time than participants who took command of other surface vessels and aviation squadrons.

In addition to meetings with the ISIC and, when applicable, operational commander, participants also requested briefings from ISIC staff members relating to readiness and operational schedules. These meetings offered the participants additional information about the unit's personnel, history, and upcoming schedule. Meetings with key players external to the Navy included shipyard managers, engineers, port authorities 
and navigational pilots. The purpose of these meetings was to obtain information to increase familiarity with repairs, maintenance schedules and safe navigation particular to the location.

In several cases, the participants described arriving at the unit's location with enough time to meet with a person from the crew, usually the executive officer, or with a group of people, such as key department heads, away from the unit prior to the assumption of command. These encounters were normally conducted in an informal setting, such as a restaurant or a home, and described as important in obtaining information about the crew or the culture that existed within the crew or wardroom. In one case, the participant described arriving unexpectedly at an informal meeting of the wardroom. Instead of finding the entire group of officers, as he expected, he noticed the absence of a particular group of officers, which provided him a key data point in his assessment of the culture of the wardroom. This participant characterized the wardroom as "fragmented". He had been directed by higher Navy leaders to fix the unit's climate. His first observation was later strengthened as he observed other symptoms hindering teamwork such as a lack of mentoring, no open communication and the absence of negative feedback among the officers in the wardroom.

The preparation phase for the participants was a period of information gathering and, when necessary, personal requalification. It was common for the participants to explain that they were reluctant to arrive with any preconceived notions, instead relying on their personal observations and assessments of the crew and unit in order to figure out what to do. It was also common to hear participants express a reluctance to rely exclusively on the conclusions within a written investigation or report. Participants 
admitted investigations and reports could be helpful in identifying what had occurred with regard to a specific incident, but that they most likely would not completely reveal underlying causes that might have contributed to the event or what was currently happening with the crew.

Arrival at the unit and incoming change of command. Each story, told by a participant about his arrival at the unit, was unique. The cases covered scenarios from an unfamiliar and impersonal arrival to the closest possible relationship between the unit and its commanding officer, as shown in the following two contrasting quotes: the first in which the participant described driving past the relieved commanding officer, who he did not know, as he approached the unit in his car:

The CO, who had just been relieved, was walking, [the ISIC] had just relieved him, and he was walking down the pier. Didn't make eye contact with him. Just kind of slowly drove down the pier, with my bag and baggage, asked for an escort up to my cabin, because I had no idea how to get there. Never had been on a [class of ship] before. In the second situation the participant was physically at the unit engaged in problem solving with the commanding officer prior to his relief when the ISIC phoned and requested his presence in his office. This participant met with the ISIC, returned to the unit and took command less than two hours later.

I had been in the room with the $\mathrm{CO}$ for the past seven months. I helped him or tried to help him get through the series of inspections and certifications that he was struggling with... kind of unusual because the $\mathrm{CO}$ told me that I was going to, he said that I was taking command before the ISIC told me...right after the 
phone call... I hung up and said, "The ISIC wants me to come over," and he said, "yeah, you're probably going to take command."

Eight of the 11 participants commented on they way they knew the officers who they relieved. Two offered that they thought highly of the officers or really liked them, two referred to them as Naval Academy Classmates and friends, two called them friends and three more called them good friends. Only three of the participants did not offer an explanation about their relationship to the previous commanding officer. One of the participants who didn't mention previously knowing the former commander did say that he felt sorry for him because he had pointed out some of the Navy's underinvestment issues to senior leaders and they had not paid attention to the reports. Another officer who called the relieved commander a good friend mentioned that it was fortunate for himself that the friend was already gone when he arrived because a turnover of the unit from that friend would have been more difficult. One participant recalled feeling sad and disappointed for the man he knew, and another felt angry when he heard of the incident that caused his good friend's removal.

The participants commonly described a meeting with the ISIC or his deputy, either in person or by phone, during which they orchestrated the participant's arrival at the unit. Some participants made input to the plan, whereas others were briefed on how events would unfold. There were a few cases in which the events that were planned or briefed did not unfold as the participant had expected and one case in which the participant remarked that during the assumption of command, in front of the assembled crew, he was surprised by the lack of previous attention that the ISIC seemed to have placed on preparing any remarks at all. In many cases the relieved commanding officer 
had already departed the unit and the unit had an acting commanding officer, usually the Executive Officer or a member of the ISIC staff. The interviews revealed that when events deviated from the agreed or briefed plan it was usually related to the ISIC's attempt to prevent additional embarrassment to a commanding officer who was still at the unit.

The participants experienced different scenarios when assuming command of the unit. The most commonly described scenario was one in which the participant was escorted to or met at the unit by the ISIC. The ISIC introduced the participant to the crew and some explained the reasons for the relief of the previous commanding officer. Then the participant was given a chance to speak. In most cases, the event was designed to mimic the sequence of events of a traditional assumption of command, set in Chapter 8 of Navy Regulations (Department of the Navy, 1990), which directs the mustering of the crew and the incoming commander reading his orders.

Only the participant who had the longest period of time between notification and travel recalled having received written orders directing him to assume command of the unit. The other participants stated they had not received official orders. Some participants drew from the orders they had received for a previous command tour and composed a similar phrase to read in front of the crew. Others followed the Navy's standard script during relief of a watch in which the relieving officer states, "I relieve you sir," and the officer relinquishing command replies, "I stand relieved." In one case, the symbolic act was performed in front of the wardroom instead of the crew. In that case, the ISIC explained to the assembled officers why he had relieved their commanding officer, introduced the new commanding officer and removed the command-at-sea pin from the 
left side of the participant's uniform shirt, where it indicated he had previously held command and re-pinned it to the right side, which indicated he was now in command. In two cases, the notification to the crew was done electronically: one by announcement over the ship's public address loudspeaker and the other by the ship's television. None of the participants remarked about or expressed any feeling about the lack of written orders, but in most cases some legitimizing or symbolic action was taken that would be recognized by the crew.

\section{Interim Command Leadership}

The participants in the study all took command of ships, submarines, and aviation squadrons with operational goals and timelines. Interim commanding officers were normally given a formal goal, usually an operational goal, by their higher level of command. The directions from higher levels of command included the following orders: get the unit underway today, get the unit underway within a timeframe, pass the reinspection within a timeframe, participate in an exercise within a timeframe, participate in a mission within a timeframe, get the unit ready for war, and fix the command climate. Participants generally mentioned feeling the need to first convince themselves the unit could operate safely. Then they considered the units' ability to perform a mission or deployment by examining personnel and material readiness and then reviewed the organizational culture. The command leadership phase of the timeline contained the actions and interactions used by interim commanding officers to get the unit to achieve the operational imperative and prepare the unit for the arrival of its next commanding officer. Interim commanders had a limited time within which to complete an assessment, 
make decisions about priorities and focus areas, and engage in necessary cycles of transformation.

Immediate actions. The immediate actions of interim commanding officers were targeted at communicating the standards of conduct they expected to crewmembers and gathering information to complete their assessment. A set of group meetings with the wardroom, Chiefs Mess, and remaining crewmembers was normally conducted as a formal introduction, a conduit for explaining their leadership philosophy, standards, and expectations, and for answering questions. Longer meetings were conducted with the executive officer and senior enlisted advisor, usually together. During these meetings a division of responsibilities and the necessity of maintaining cohesiveness in front of the crew were discussed. Participants who had taken command of submarines placed more emphasis on cohesiveness within the command triad than other participants in the study. Individual meetings with department heads were conducted for the purpose of discussing personnel, material and operational readiness.

All participants asserted that building trust with the crew was an essential step in succeeding. They all felt they had to have the trust of the crew, in order to achieve the operational imperative. Conversely, all participants expressed their concern with determining who in the crew they could trust upon arrival. They wanted the most accurate assessment of the problems that existed. To compensate for the uncertainty of whom to trust, interim commanders relied on the person or people who they brought with them to the unit as assistants, the people they knew from previous assignments, and the people in units nearby who had been recommended to them by people who they knew and trusted. 
Several participants recounted their deliberate mention of trust in their first meeting with the crew. One participant made it the focus of his remarks just after assuming command.

I took command at 0630 . I just stood on a [maintenance platform] and said, "I'm your guy. I know you don't know me. You have no reason to trust that I'm going to be any good whatsoever. I'm going to work my tail off and earn that trust."

In two other cases the participants knew that the crew and their families were very worried about the impact of the incident affecting the crew's normal holiday leave schedule. Airline tickets had already been purchased and sailors would lose money if the schedule changed. Interim commanding officers used the first meeting with the crew to assure them that their plans with family would not be impacted, which helped alleviate uncertainty and establish trust with the crew and their families.

Additionally the first communication to the crew usually contained a description of what actions would cause discipline to be imposed on a crewmember. Violations of trust, lack of integrity, lying, and willful breaking of rules would be punished, whereas honest mistakes would be corrected through examination of practices and training. This philosophy was described by almost all of the participants as a way to explain their leadership style, avoid a zero defect mentality, where the crew might be motivated to conceal instead of discuss discrepancies, and a desire to build a learning culture based on honest self-assessment within the crew. Communicating standards and holding people accountable through fair and equitably enforced discipline was also viewed by interim commanders as an important element of establishing trust with the crew. 
In the cases where interim commanders stepped into units with poor material condition or where the crew had just failed an inspection, they were very direct with officers and chiefs during initial meetings about the contributions of people within those groups to the poor material condition and readiness of the unit. They communicated their standards and warned them that they would be held accountable and that they in turn needed to prove their trustworthiness to the commanding officer. Some participants recalled reports from the senior enlisted advisor or their assistant about negative responses to this message from some members of these groups, while also hearing positive or optimistic comments from other members who thought that it was, "about time" procedures and standards were to be changed.

Assessment. Assessments had to be done very quickly. Information gathering continued for the first several days on board but was occasionally limited due to performance of the unit's operational mission. One participant explained:

So we had to quickly identify what needs to change right away, before we even get underway. Are there some unsafe procedures, things in writing that need to be done differently and if it wasn't what we thought was essential to the safety of the ship, then we'd give it some time.

As part of information gathering, one participant mentioned interviewing all the officers personally, but not the chief petty officers. He had wanted to interview the chiefs, but ran out of time. Generally interim commanding officers found the time to meet with their executive officer, senior enlisted advisor and key department heads while making their assessments. 
Participants also personally inspected the material condition of their units by walking around it and physically seeing the state of the equipment and personnel and who among middle management was present at key times. One participant told a story about personally inspecting equipment and then personally documenting the large number of discrepancies on maintenance requirements forms. He was deliberately demonstrating his interest in the material condition of the equipment. Participants choreographed this aspect of their information gathering to model the level of involvement they expected from their senior and middle managers.

Most participants described completing their initial assessments in a matter of days, although later during interviews they spoke about "peeling back the onion" and finding additional problems affecting practices, procedures and organizational culture. Some interim commanding officers commented that previous experiences, most often their previous command tour, had given them the skill to make quick assessments and judgments about personnel. Some stated that although the situation was challenging, they felt they knew what to expect from the crew and what things should look like at the unit. They admitted the arrival and assessment would have been harder without their previous experience in command.

Priorities and focus areas. As a precursor to being able to confidently say the unit was ready to perform its mission, interim commanders were likely to concentrate first on safety, second on personnel and material readiness and third on changes that needed to be made in the organizational culture. When safety was reported to be of concern in an investigation or report, or if it was unknown by the commander prior to his arrival, it was described as the first priority. Specific attention was placed on assessing deficiencies in 
the areas of navigational safety, flight safety and safe maintenance practices. Once satisfied that the unit could operate safely, the second priority was readiness. Readiness was examined in two general categories, (a) personnel, including training, proficiency and mental state, and (b) material condition of the unit and its equipment. One participant described "living in engineering" for three weeks in order to become confident that he understood the extent of the problems and that the right procedures were in place and being performed before he was able to shift his focus to another area that needed attention at the unit. Most participants stated that they became aware of problems with the organizational culture as they focused on readiness.

Cycles of transformation. In the course of their interim command tours, most participants continued to evaluate crew performance to determine causal factors in procedures, policies and within the organizational culture that may have contributed to the incident or series of events for which the previous commanding officer was held accountable and relieved. About half of the participants used the term peeling back the onion to describe the mindset of examining each problem as a possible symptom of a deeper more systemic problem, or root cause. In the words of one of the participants: I was always tenacious about peeling the onion back. OK, if we have a problem on board, you've got a symptom of it, you've got to critique it, peel back the onion, find out what the root cause is, sometimes that's painful because you find things you don't want to find.

One participant related peeling back the onion to developing trust with the crew. He explained that the crew needed to trust that they wouldn't get things by the system and also that the climate within the unit would support honest disclosure of bad events in 
order to develop a learning organization that was capable of self-assessment. Participants sought to change the organizational culture to achieve this capability by communicating and enforcing standards, modeling involvement behaviors, and increasing perceptions of fairness.

The short duration of the tour and the process of peeling back the onion caused some interim commanders to re-evaluate what they would be able to accomplish. Describing his awareness of the limited time he had, one participant explained:

Yeah, it became obvious after less than a week that I wasn't going to make a lot of change, a great deal of difference. So my goal kind of shifted from turning over a working ship to turning over a ship to the incoming $\mathrm{CO}$ that could get better. The participant knew that he could not significantly improve the material condition of the ship within the timeframe that he had and concentrated instead on identifying the current condition and developing a path forward, while educating the crew.

In several situations, participants described how they became aware within days that certain key department heads and chief petty officers, due to their attitudes or abilities, could not remain in their positions. Interim commanding officers relieved department heads, officers and chief petty officers of their duties by firing them or transferring them, if the participants believed that those members would hinder the crew from progressing in the desired direction. In several cases, the interim commanding officer made a specific request for a department head or senior enlisted advisor to come to the unit. In only one case, the participant described resistance from the ISIC that resulted in him not being able to get the right person into a key position.

\section{Departure}


The departure of the interim commanding officer signaled the return to a normal condition to both internal actors (crewmembers) and external actors (higher Navy leadership, spouses and families, and the public). In some cases, participants described being aware that they would not have the time to see the desired effects of their actions or witness the outcome of the changes that they made while they were in command at the unit. Other participants explained that they were envious of the new commanding officer because they had prepared the unit for a mission and wouldn't get to deploy with the crew or stay with the crew as they accomplished the mission.

Outgoing Change of Command. Participants described how they did not desire to have a big ceremony for the transfer of authority to the new commanding officer. If senior leadership attended, it was usually the ISIC. Some participants recalled asking the ISIC not to attend and if they did, to only speak about the accomplishments of the crew. They did not want to draw attention to themselves or their accomplishments. They described wanting to hand the crew over to the new commanding officer without fanfare. It was usually the senior enlisted advisor who drew attention to the crew's need to see the actual transfer of authority, as described in Navy Regulations, especially when they had not seen the assumption of command when the interim commanding officer arrived. So it was common for the participants to describe a formal transfer of authority, performed in front of the crew, but not performed in dress uniform. The notable exception was the case with the most severe effect on the crew. In that case, the unit conducted a formal transfer of authority with the ceremony also culminating the unit's accomplishment of its first assigned mission. 
Personal interpretations of the experience (Internalization). The expression of being confident in their own leadership ability, especially due to their previous experience in command, was one of the strongest themes to emerge from this study about interim commanding officers. All had previously held command of an operational Navy unit. For each participant, his level of confidence in his own leadership ability entering the interim command experience was greater than in his first command tour. The assignment was always described as rewarding, but challenging:

I think that the situation challenged everything that I had experienced in leadership, both in my own command in observing leaders under stress through my career, whether it's being somebody that the XO could talk to, level with, and the command master chief, and then providing encouragement, guidance, prioritization. I guess the biggest thing that I did was setting the priorities for the command, but also just making sure that they knew how to deal with what had happened, and helping them interpret what it meant to them, and how they can grow beyond this.

The data revealed strong justification for the continued practice of assigning an officer with previous command experience in situations of Commanding Officer Detachment For Cause (DFC). All participants in the study felt that the assignment of an interim commanding officer was appropriate for the situations which they entered and felt that they, themselves, were qualified and capable of performing the assignments. Appendix D displays the participants' comments, which appeared throughout their interviews, explaining the benefits of selecting an officer with previous command experience. The data was grouped by the researcher into the following categories: (a) confidence in own 
leadership ability, (b) restoring organization or external confidence in command leadership, (c) restoring organization or external confidence in unit readiness (d) restoring crew confidence in command leadership, and (e) restoring crew confidence in unit readiness.

\section{A Model of Restoring Confidence through Interim Leadership}

Close examination of the themes revealed in the interviews led to the development of a model to explain how interim commanding officers navigate through the experience of providing interim leadership to operational Navy units in a context of unknowns. Figure 1 presents a model displaying the conditions, actions and interactions, and outcomes that constitute the interim leadership experience.

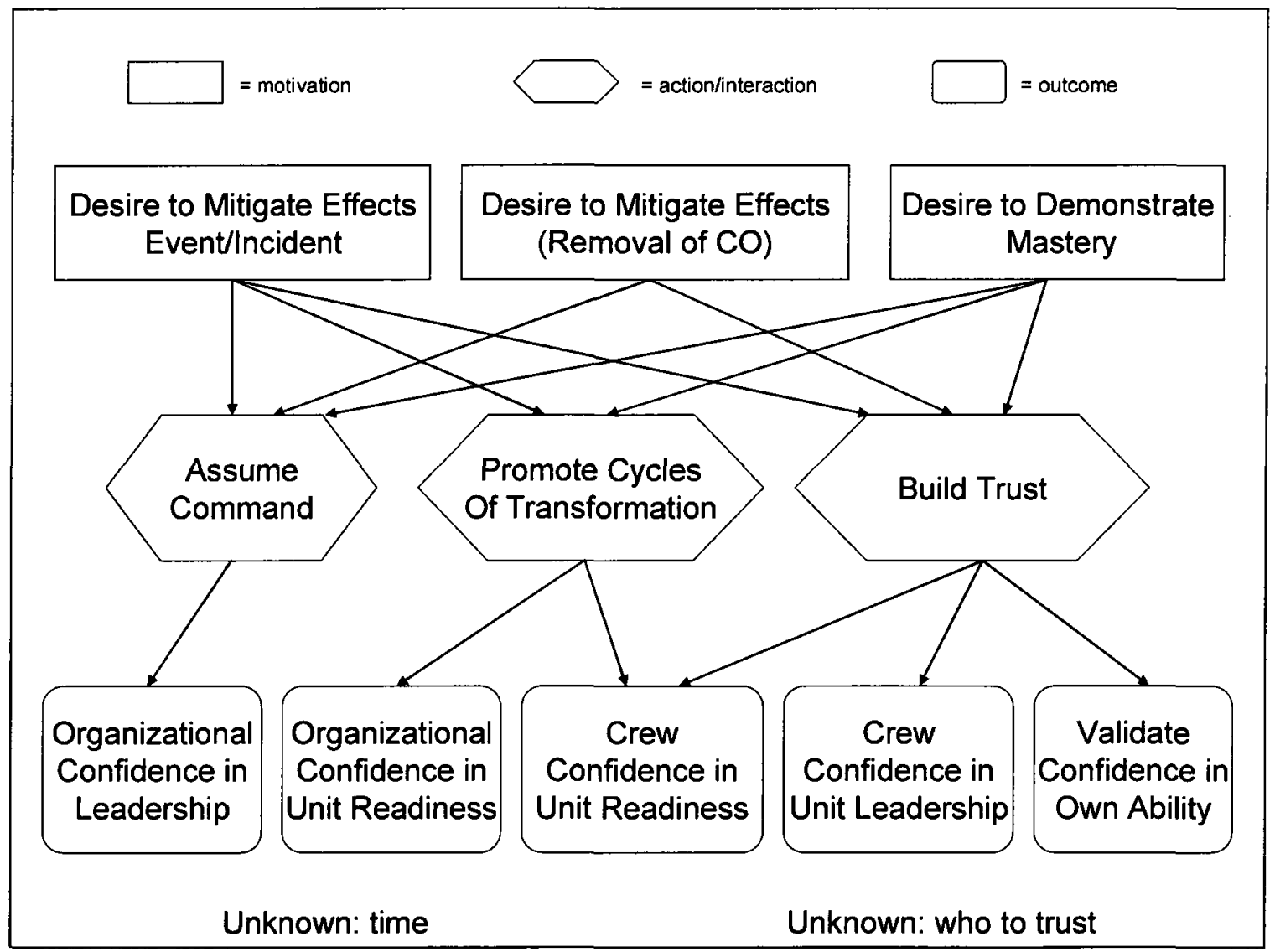

Figure 1. A grounded theory model of restoring confidence through interim leadership 


\section{Leadership Challenge: Dealing with the Unknown}

The interviews revealed two categories of leadership challenges, those that were associated with the experience of being an interim commanding officer and those that were associated with the unique situation that each unit presented. Challenges that were described by participants were grouped by the researcher and listed in Appendix E. All interim commanders experienced challenges about the unknown and who they would be able to trust, related to the experience of being an interim commanding officer.

Some participants described not having access to the investigation about the incident that caused the previous commanding officer's removal, however, some did have access to a copy of the preliminary investigation or inspection results. Those who did described how these reports made them feel nervous or increased the concern they had about the situation that they would find at the unit. The duration of the assignment was also unknown and most interviews revealed that the participants did not know the timeframe within which they had to work. Gaps in their personal qualifications or experience were identified as a concern. Some had commanded the exact kind of unit in their first command tour, whereas others had command of similar units that had some technical differences or differences in mission focus.

Getting the best information they could about the unit was important to the participants. However, participants reported that they viewed reports and investigations simply as a source of information and remained committed to developing their own opinions after arriving at the unit and examining what they found, particularly about underlying causes that could have contributed to the incident. One participant cautioned: 
It's real easy to read into the investigation, to have heard things, get some phone calls, and start making generalizations about what the crew can and cannot do. And, while a lot of that may be true, you need to read the investigation very carefully. And I needed to make sure I understood what mistakes were made. It's easy to connect dots that maybe shouldn't be connected, and to draw conclusions that shouldn't be concluded, and make generalizations about the crew, etc. So, I tried to give the benefit of the doubt wherever I could.

Participants were likely to express a deep concern about what they would find in terms of operational safety and mission readiness and described their awareness of the consequences of getting it wrong. They were interested in the opinions of higher levels of leadership in the unit's chain of command about the incident, and the unit's culture and readiness and the opinions of people with whom they had previously developed a trust relationship about the unit's safety and mission readiness.

\section{Causal Conditions}

In this study, the motivations of interim commanding officers were examined independent of the decision to remove the previous commanding officer. The decision to remove the previous commanding officer was made at a higher level than the participants of the study and occurred previous to the notification of the participant. This study does not comment on those decisions. Three conditions were revealed as motivations of interim commanding officers: the desire to mitigate the effects of the event on the unit, the desire to mitigate the effects of the removal of the previous commander on the unit, and the desire to demonstrate mastery in command. 
Desire to mitigate effects of the event or incident. The units and crews represent strategic and tactical assets of the U. S. Navy. Effects of mishaps, events and incidents affect the operational schedule of other units and national security. Participants were highly motivated to help the unit recover from the effects of whatever event or condition affected the capability of the unit by a sense of duty and responsibility. As one participant explained, "It was going to be a big job, and I didn't want to let down the Navy. I felt like they had put special trust and confidence in me."

Desire to mitigate effects of the removal of the previous commanding officer. Effects on the wardroom and crew from the removal of the previous commanding officer ranged from very low, in cases of personal misconduct, to very high, in cases where the wardroom and crew had strong attachments to the commanding officer. Participants felt an obligation to help whoever was affected move past the event, both personally and professionally.

Desire to demonstrate mastery. Overwhelmingly the participants of the study indicated they desired the assignment. For example, one of the participants said, "To me, there is nothing more rewarding than being able to get a crew together and accomplish a mission and watch them having their success." Participants also expressed feelings of satisfaction about their first command tours. Some expressed regret that commanding officers often only have the chance to command one time in 20 or more years of experience, and that they had thought they might not have the chance to command again. Their feelings of being qualified and capable and positive feelings about previous experience in command indicate that the command experience generally is one of demonstrating mastery, akin to the term flow often used by musicians during 
improvisation sessions. Participants described the opportunity of a second command experience as either an opportunity or a gift. The study obviously included only participants who had accepted the assignment as interim commanding officer. There was no way to capture information about officers who turned down such an assignment, or why.

\section{Actions and interactions}

Assuming command. The assumption of command of the incoming officer signaled a restoration of confidence in the unit's commanding officer by the external actors in the Navy organization. In cases where the effect of the incident was associated with the leadership of the previous commanding officer, the change in leader also signaled an end to that association and the possibility of new opportunity.

Promoting cycles of transformation. In addition to taking corrective actions to respond to the training and the material deficiencies that they found upon arrival, interim commanding officers continued to investigate root causes of problems they observed. When interim commanding officers discovered root causes, they used a variety of strategies to show or illustrate the systemic problem to the crew and reinforced the message with modeling behaviors and communication to influence transformational changes within the wardroom and chiefs mess. An example of symptom and root cause analysis is located in Appendix F, Integration of Symptoms and Root Causes.

Building trust. All participants knew that to succeed, whatever their directive, they had to build trust with the wardroom, Chiefs Mess and crew. At the same time they needed to express trust in the crew. "Leading by example" (modeling desired behaviors) was the phrase most commonly used by participants in the study to characterize the 
leadership behavior they thought was most important in their experience as an interim commanding officer. However, as the data in Appendix G, Described Behaviors of Interim Commanding Officers, shows, communication was the behavior they most often described when explaining how they responded to the challenges they faced with all internal and external actors and was an essential part of building trust with the crew. Interim commanding officers explicitly communicated standards and expectations to the crew and engaged officers and chiefs (senior and middle management) to ensure compliance. Standards and expectations were communicated verbally, in writing and through modeling.

Getting themselves qualified and familiar with the unit, especially in regard to personal qualifications, was also very important to participants. They described feeling that they had been selected because of their previously demonstrated success in command, a possibility they now embodied for the crew. Participants implied that in operational Navy units the commanding officer's past performance increases his legitimate authority and that his knowledge and expertise are also directly tied to crewmembers' motivation to achieve their own qualifications and the unit's operational safety and mission success. Therefore, interim commanding officers desired to rapidly overcome any unfamiliarity or deficiencies in their knowledge about the unit, demonstrate the commitment to proficiency they desired to see among crewmembers and ensure the crew's perception of their legitimate authority. This supported the study done by Barbuto (2000) in which follower-based influence triggers were examined. Barbuto identified three categories of follower compliance based on follower motivation and proposed a hypothesis that follower compliance would be more likely if leaders targeted 
their zones of least resistance. In the context of the interim commanding officer experience, followers might have less resistance to power (role and expertise) or values (internal attribution and goal identification) derived triggers.

\section{Outcomes}

It is difficult to identify the elements that would measure the goal achievements of interim commanding officers without a broader quantitative study. The duration of the command tour of duty was short relative to a normal command tour and metrics were not used to examine the actual causal relationships between actions and outcomes of the participants involved. Anecdotally, the men had access to information about future successes and problems of the unit. They maintained relationships with certain members of the crew and gathered data formally and informally. The interviews of these men occurred years after their experiences. While most participants expressed negative feelings about having to depart the unit prior to having evidence about the long term outcomes of their actions, their justification of the experience indicates that they believed that they demonstrated mastery and that their leadership as interim commanding officers was of benefit to the crews of the units they led and to the U.S. Navy organization.

\section{Conclusion}

This chapter documented the stories of 11 interim commanding officers throughout the duration of their command tours by grouping specific common experiences into categories comprised of the arrival phase, interim command leadership phase and departure phase. Data analysis of the conditions experienced by the participants, the actions and interactions they used to deal with the problems they encountered, and consequences they described clearly indicated that restoring confidence 
was the core category of this study. A model emerged that clearly linked major concepts and offered an explanation of how confidence was restored through the leadership of interim commanding officers. 


\section{CHAPTER 5}

Discussion

Summary

In chapter one, the researcher introduced the reader to the problem facing senior leaders in the U. S. Navy when a commanding officer of an operational unit is relieved of his or her command. The study provided background information about the selection process, role, and authority of commanding officers and described the process that is followed when a commanding officer is relieved. To help the reader better understand the study, definitions were given for terms relating to the field of leadership and terms related to navy organization and command authority. The study also found there is a gap in leadership literature documenting and interpreting the experiences of interim commanding officers in the U.S. Navy. The goals of the study were to begin to build a body of leadership literature documenting and interpreting the experiences of interim commanding officers in the U.S. Navy and to provide valuable information to future interim commanding officers and the senior leaders who would select the interim commanding officers and guide these leaders during their efforts.

Chapter two presented a review of the literature covering themes in leadership, organizational culture and planned change within organizations. The data analysis during this study caused the researcher to consult the literature about group cohesion in Navy operational units. Although there is a rich body of literature discussing military group cohesion in U. S. Army combat units and army combat units in other countries, there are gaps in the literature discussing factors that influence group cohesion of Navy crews and 
groups within navy crews, and also gaps in the literature detailing crew perceptions of combat readiness related to leader performance in operational Navy units.

Chapter three outlined the research method used to collect, analyze, and display data. The researcher drew on elements of phenomenology to extend her understanding and document the experience of interim commanding officers. With that background, the researcher then examined the data for the experiential and situational contexts. Utilizing the constant comparative process developed in Grounded Theory Method (Strauss 1987, Strauss and Corbin 1998) the researcher analyzed the data and developed theories about how interim commanding officers dealt with the experience of being an interim commanding officer.

The study examined contextual information concentrating on depth of understanding and systematic exploration of themes. To address internal validity and reliability, the researcher hoped to provide transparency in the research method by offering an explanation of the study design, and data collection and data analysis processes. The theoretical sampling technique that falls in line with Grounded Theory methodology was used in this study. It was designed to provide an initial contribution to leadership literature, which can be further researched by studying larger populations and testing hypotheses utilizing quantitative methods. The findings of the study should not be generalized to other populations due to the small size of the participant group, the fact that not all types of operational units were represented in the sample of participants and there was not uniformity across size or type of unit.

In chapter four, the study revealed participants had similar experiences related to being an interim commanding officer and differing experiences related to the unique 
situations they found upon arrival at their units. Interim commanders experienced a common timeline consisting of (a) arrival, which was comprised of awareness of the event and notification, preparation, and incoming change of command; (b) interim command leadership, which included immediate actions, assessment and identification of priorities and focus areas, and promotion of cycles of transformation; and (c) departure, which incorporated the outgoing change of command, and internalization of the event. Depending on the situations they entered, interim commanding officers responded to the unknown, by first assuring themselves of operational safety, then focusing on personnel and material readiness, and the operational mission, and finally, when needed, cultural change.

A model was developed to illustrate how interim commanding officers dealt with the experience of being an interim leader. Interim commanding officers were challenged by the unknown during their assignment, including: (a) unknown timeframe, and (b) who they could trust within the crew. Regardless of the situations they found upon arrival, participants recognized a need to build trust with the crew in order to achieve their directed goals from higher levels of leadership. Interim commanding officers focused on communication and modeling desired behavior to restore confidence within the command triad, with the officers of the wardroom and Chiefs Mess, and with the crew.

\section{Significance of the Study}

This chapter presents a discussion about the significance of the findings and how the study supported the goals of the researcher. The study, through an in-depth and systematic exploration of the experiences of 11 participants, provided data to answer the following research questions: (a) what were the experiences and leadership challenges 
faced by interim commanding officers? (b) which experiences, if any, differed from their first command tour? (c) what observations were made by interim commanding officers about the organizational culture and morale of the wardroom upon their arrival and departure from the unit?(d) which leadership behaviors and strategies, if any, did interim commanding officers find useful to change the organizational culture and morale of the wardroom?

\section{Research Question (a): Experience and Challenges}

The study detailed the experience of being an interim commanding officer from awareness of the incident that caused the relief of the previous commanding officer through the interim commanding officer's departure from the unit. Retrospectively, the experience of being an interim commanding officer was positive for all participants of the study. They reported feeling a higher degree of confidence in their own leadership ability than they had felt when entering previous command tours. They enjoyed the experience of demonstrating mastery through commanding a Navy unit again. They felt rewarded by the selection and from the experience. Interim commanding officers were able to justify the experience with positive comments, expressing appreciation for the experience and feelings of honor and reward upon completion of their tour of duty as an interim commanding officer, although no public acclaim or award was given to them. The data revealed that participants gave the following justifications for assignment as an interim commanding officer: (a) confidence in own leadership ability, (b) restoring crew confidence in command leadership and mission readiness, and (c) restoring organization or external confidence in command leadership and mission readiness. 
The assignment as an interim commanding officer is replete with challenges relating to each unique situation and the experience itself. Common challenges were identified in chapter four and depicted and illustrated in the grounded theory model. While it is impractical to list all of the challenges faced and the strategies for overcoming these challenges in this text, the researcher compiled a guide for future interim commanding officers, which is to be found in Appendix $\mathrm{H}$, Advice for Interim Commanding Officers: Mitigating Challenges of the Assignment.

\section{Research Question (b): Comparison with First Command Tour}

The study showed that interim commanding officers have to figure out how to deal with the experience of being an interim commanding officer and they have to figure out how to deal with the situation into which they are thrust. The challenges of dealing with uncertainty and compression in the timeline preceding arrival, an uncertain situation upon arrival, and also uncertainty about who can be trusted upon arrival at the unit were commonly attributed as different from the first command experience. The interim commanding officer experience was described as more challenging than their first commanding officer experience. However, it varied by participant whether the perception of increased challenge stemmed from the situation or the experience.

When participants in the study mentioned having excitement about the opportunity to command again, they followed or qualified the comments with statements describing how much they hated that the need for an interim commanding officer was there. Being an interim commanding officer was an experience which caused the officer to reconcile his strong desire to command again and the certainty of his ability to succeed in the situation with an intense sorrow that the organization had the need for his services 
as an interim through the failure of a commanding officer. The reconciliation process appeared more complex when there was a personal relationship between the interim commanding officer and the officer whose position he filled. Witnessing failure, particularly public failure, of a fellow commanding officer was disturbing. Seeing a friend fail in command was a profound experience for the participants. It was described by one of the participants as "a heart wrenching experience to see him go through what every CO dreads". Conversely, being selected to command again in a difficult situation validated the officer's perception not only of having had a successful first command tour but also the value of his career's worth of experiences. Selection for the assignment by senior Navy leaders corroborated the self-assessment that the officer's expert knowledge, judgment and ability were exactly what was needed and were deserving of the special trust and confidence of senior Navy leaders and the Navy organization. Interim commanding officers seemed to respond to the duality of emotion by exhibiting selfsacrificing behavior and humility about the selection and during their assignment as interim commanding officers. There were no indications of desire for career advancement or personal recognition in the participants' descriptions for taking the assignment.

Participants described experiencing an awareness of time that was different from their first command tours, but most expressed that they consciously did not limit their focus for the unit to their limited timeframe. With two exceptions, the participants set the course for the unit ensuring that long range planning occurred. In the cases where that did not occur, one was the case with the most severe effect on the crew and the other in the case of the shortest duration in command. 
Participants had varying degrees of neutral to negative reactions to the term interim commanding officer used in the study. All asserted they felt like commanding officers with the same level of authority, responsibility and accountability as in their first command tour. One participant admitted he used the term interim commanding officer in his official military biography, a single page document listing the officer's accomplishments. Another participant's biography mentioned that he had taken command without a band. So, while participants understood the usage of the term, acknowledged it as being part of the vernacular, and even used it to describe themselves or commanding officers in other situations, they did not like to have their command experience qualified in any way. One participant emphatically expressed, "I never once thought of myself as an interim CO." The researcher could only conclude that while he is exercising command authority of an operational Navy unit, the experience of an interim commanding officer is to be in command!

\section{Research Question (c): Observations about wardroom culture and morale}

Morale was affected in the wardroom, Chiefs Mess and among the crewmembers due to the removal of the commanding officer, the stigma or trauma from the incident or condition of the unit, and each group's perceived involvement with the incident or condition of the unit. Morale was also affected by other factors not related to the incident. Those factors, which the researcher categorized as remoteness factors, included: overseas homeport, geographic isolation from other units of the same type, outdated or legacy equipment, different deployment or utilization schedules compared to other units of the same type, whether or not the unit was deployed at the time of the incident, and crew identity. Interim commanding officers indicated that remoteness factors, while 
contributing to crew cohesiveness were occasionally strong barriers to changing the morale and organizational culture of the wardroom, Chiefs Mess and crew.

Research question (d): Changing wardroom culture and morale

Depending on the situational context into which they entered, the assessment they performed upon arrival, and root causes they discovered during the course of their assignment, most interim commanding officers sought to change different aspects of the organizational culture of the wardroom Chiefs Mess, and crew including morale. Theoretical sampling was used in this study to provide the broadest range of data for the survey. This offered data about the severity of the effects on the wardroom and the crew. Sometimes, there was either minimal or no impact on the wardroom and crew or conversely, traumatic impact on the wardroom and crew.

Interim commanding officers commonly described placing some level of attention on the emotional management of the crew. One participant offered this explanation of the effect of the incident on the morale of his crew:

And I knew that the [unit] was in an emotionally delicate position. So in some ways there was a bitterness because this happened to them in sort of a, "this can't possibly happen to us, we're a great [unit]," sort of attitude and feeling of invincibility, and just a lack of understanding and belief that this occurred. But on the other hand, they were sort of emotionally shattered too, because it's vey embarrassing to lose a [commanding officer] they all respected, and to have what would have been a great deployment and turn it into a disaster.

There were differences in the amount of time and attention placed on emotional management of the members of the wardroom due to the effect of trauma or stigma from 
the incident. For example, this study included one case in which the participant arrived at the unit after the commanding officer had been relieved for personal conduct. The crew was unaware of the actual reason for the removal and there were no crewmembers who perceived that they had any association with the removal of the commanding officer. In this case, the interim commanding officer was only concerned about the impact on one officer among the entire crew. In another case, less than 10 members of the crew had any association with the single incident that caused the relief of their commanding officer. The interviews of these participants revealed that their experiences of the arrival phase of the timeline paralleled the experience of other interim commanding officers with regard to notification, preparation and assumption of command but their situational experience regarding efforts to change the morale of the wardroom was less likely to be similar. The following hypothesis could be tested in a future study: as severity of the incident decreases, emotional management of the crew as a priority of the interim commanding officer decreases and may be limited to only those crewmembers directly involved with the incident.

In contrast, one of the cases followed a serious event resulting in severe damage to the unit and loss of life among the crew. The difference in the experience of the interim commanding officer in that case, regarding wardroom and crew morale, could be explained by the severity of the effect of the incident, which the event left almost all of the crew aware that their lives had been in danger. In this case it is likely that that the crew experienced the event as a survival experience, as opposed to a stressful experience. The literature supports differentiating between the effects of stress and survival experiences on group cohesiveness and perceptions of combat readiness. This theory is 
supported by the remarks of the interim commanding officer in a different case, one that also resulted in the death of a crewmember.

The crew relived some of the emotions and the trauma when they got home, for obvious reasons. Come back home and all of a sudden realize how close I came to maybe not coming home, or whatever. Just all that emotion, hey my shipmate didn't come home, my friend didn't come home with us.

The following hypothesis is offered for consideration in a future study: As severity of the incident increases, emotional management of the crew, as a priority of the interim commanding officer, increases and may compete with, limit or surpass other goals and priorities.

Remoteness factors, as listed previously, could have a positive effect on crew cohesiveness and a negative effect on organizational culture. A hypothesis was also formulated to suggest areas for future quantitative studies which could test factors impacting the effect of removal of the previous commanding officer on the crew as well as contributing to resistance to cultural change: the degree of the impact of the commanding officer's removal on the officers of the wardroom increases with the officers' familiarity with the Commanding Officer, duration of the deployment, remoteness factors, perceived association with the incident, severity of the incident, and public awareness of the incident. This hypothesis should be tested for crewmembers and the Chiefs Mess as well as officers and the results compared to assess if there is significant difference between the groups. 


\section{Implications}

There was an inconsistency with the interim commanding officers' commitment to restoring confidence and the organization's commitment to restoring confidence. United States Navy Regulations governs the process of a captain assuming command of a vessel. “....all hands shall be called to muster and the captain shall read his orders and assume command." In only one case had the administrative paperwork been accomplished to formally charge the interim commanding officer with the appropriate authority to assume command. The process should be legitimized through the formal issue of a written order prior to arrival at the unit. To contribute to the legitimate authority of the incoming commander, the actual written order should be read by the interim commander upon his arrival at the unit as part of the incoming change of command or assumption of command or during introduction to the crew.

Future interim commanding officers. The study contributes to the body of research on interim command leadership by detailing the experiences of interim commanding officers and proposing a model to explain how they deal with their assignments. It could be of great value to any officer notified of selection or possible selection for an assignment as an interim commanding officer. Additionally, tables and tools attached as Appendices, particularly Appendix H, Advice for Interim Commanding Officers: Mitigating Challenges of the Assignment, and Appendix I, Symptoms and Root Causes Survey could be very helpful to officers entering this type of assignment.

The officer selected to fill the assignment following a Detachment for Cause is not always an officer with previous command experience. The results of this study are all the more valuable to share the insights of the seasoned officers who participated. For 
commanding officers and prospective commanding officers, this study offers theories about challenges of entering command following a detachment for cause. It advises incoming commanders about potential links between observable symptoms and possible root causes in leadership behaviors of the commanding officer, the command triad, and remoteness factors in under-performing units. It also identifies factors that could be contributing to organizational cultural problems while appearing to strengthen crew cohesiveness.

For senior officers in the Navy. While there is no official category of interim command, there are situations requiring assignment of a commanding officer to provide interim leadership for short durations. There was strong justification for the continued practice of selecting officers with previous command experience for the assignment of interim commanding officer. The value of the experience of the officer chosen should weigh in the selection, especially in cases characterized by a serious event, stigma from a negative condition including the impact of the removal of the commanding officer, and remoteness factors. The assumption of command of the arriving interim commanding officer should be treated as a symbolic event, making a break with the past situation and identifying a starting point for a new condition. The transfer of authority should be carefully scripted for the effect desired. Possible effects of ISIC participation in the symbolic event would be legitimizing command authority of the interim commanding officer, communicating trust of the crew and educating the crew. Decisions about how to minimize impact on or embarrassment of the departing commanding officer should be made in advance. At the completion of an interim commanding officer's assignment, he 
should be debriefed to gather data about his experience for use in future research, to diffuse the stress of the experience, and to assist him with internalization of the event.

\section{Recommendations for Future Studies}

This study could be used to inform additional research on the following topics: to (a) test remoteness factors that contribute to negative cycles of transformation within a crew, (b) test factors affecting crew perceptions of combat readiness, (c) test crew perceptions of self-sacrificial leadership and effect on group cohesiveness, (d) test factors assessing severity of the effect of the incident on the crew. Studies should be designed to include larger groups of participants such as the Executive Officer, Senior Enlisted Advisor, members of the wardroom, Chiefs Mess and crew. Surveys could be performed soon after an incident occurs and again after the duration of an interim commander's tour following a detachment for cause.

The researcher examined how the participants described dealing with the leadership challenges they encountered in the unique situations into which they entered. Noting the tendency for interim commanding officers to engage in root cause analysis, the researcher documented several possible associations of these factors from the cases described. A future study could explore a possible relationship between observable symptoms in the crew or sub groups of the crew and their root causes in leader behaviors. The data revealed that interim commanding officers distinguished between groups within the unit's crew when describing effects of the removal of the previous commanding officer and effects of the incident on those groups. This could be attributed to the effects of the previous commanding officer's leadership style, effects of the behaviors modeled by the previous commanding officer and adopted by the wardroom and Chiefs Mess, 
effects of the incident, or effects of the removal of the commanding officer. Future assessments should therefore be conducted on three categories, the wardroom, the Chiefs Mess, and the crewmembers.

\section{Conclusion}

The study concluded that the assignment of an officer with previous command experience as an interim commanding officer fulfils the goals of restoring confidence in command leadership and unit capability to internal and external actors and that the experience of being an interim commanding officer is rewarding and valued by the officer selected. The study recommended that senior leaders in the U. S. Navy continue the practice of selecting officers with previous command experience to assume command after a commanding officer is detached for cause, particularly in situations where the incident has a high impact on the crew or readiness of the unit. This study extended the body of leadership research by offering an understanding of the phenomenon of interim leadership following unplanned succession. It also supported the existing literature in organizational culture change and group cohesiveness in military units. The study identified a need for future quantitative research to examine the effects of remoteness factors on group cohesion in operational Navy units and the impact of unplanned succession on group cohesion and readiness in operational Navy units. 


\section{REFERENCES}

Abrashoff, D. (2002). It's Your Ship: Management Techniques From the Best Damn Ship in the Navy. New York: Warner Books.

Anfara, A. Jr., Brown, K., and Mangione, T,. (2002) Qualitative Analysis on Stage: Making the Research Process More Public. In Educational Researcher, October/November 2002. Retrieved November 17, 2007 from ERIC database.

Ary, D. Jacobs, L. \& Razavieh, A. (1996). Introduction to Research in Education. (Ch. 13). Fort Worth: Harcourt Brace College Publishers.

Barbuto, J. (2000). Influence Triggers: A Framework For Understanding Follower Compliance. Leadership Quarterly, 11(3), 365-387. Retrieved August 27, 2007, from the Academic Search Premier database.

Bernick, C. N. (2002). When Your Culture Needs a Makeover. In Harvard Business Review on Culture and Change (pp. 125-142). Boston: Harvard Business School Publishing Corporation.

Bossidy, L. \& Charan, R. (2002). Execution: The Discipline of Getting Things Done. New York: Crown Business.

Bowen, G. (2006). Grounded Theory and Sensitizing Concepts. In International Journal of Qualitative Methods, 5 (3), 12-23. [On-line]. Available:

http://ejournals.library.ualberta.ca/index.php/IJQM/article/view/4367/3497.

Burns, J. M. (1978). Leadership. New York: Harper \& Row.

Caldwell, R. (2003). Models of Change Agency: a Fourfold Classification. British Journal of Management. 13(1), 131-142. Retrieved August 27, 2007, from the Business Source Premier database.

Cha, S. \& Edmondson, A (2006). When Values Backfire: Leadership, Attribution, and Disenchantment in a Values-driven Organization. In The Leadership Quarterly, 17, 57-78. Retrieved August 27, 2007 from the Academic Search Premier database.

Charan, R. (2002). Conquering a Culture of Indecision. In Harvard Business Review on Culture and Change (pp. 143-164). Boston: Harvard Business School Publishing Corporation.

Charmaz, K. (2006). Constructing Grounded Theory: A Practical Guide Through Qualitative Analysis. Thousand Oaks: Sage Publications. 
Cho, J. \& Trent, A. (2006). Validity in Qualitative Research Revisited. In Qualitative Research, 6, 319-340. Retrieved November 17, 2007 from the Academic Search Premier database

Choi, Y \& Dalton, R. (1999). The Model of Followers' Responses to Self-Sacrificial Leadership: An Empirical Test. In Leadership Quarterly, 10(3), 397-421. Retrieved August 27, 2007 from the Academic Search Premier database.

Collins, J. (2001). Good to Great: Why Some Companies Make the Leap... and Others Don't. New York: HarperCollins.

Command Leadership School_-CO Course:2007—Sample Schedule [HTML link]. Newport, RI: Command Leadership School. Retrieved December 30, 2007, from http://wwwnt.cnet.navy.mil/cls.

Conger, J \& Kanungo, R. (1987) Toward a Behavioral Theory of Charismatic Leadership in Organizational Settings. Academy of Management Review, 12(4), 637-647.

Corbin, J. \& Strauss, A. (2008). Basics of Qualitative Research: techniques and procedures for developing grounded theory (3rd ed.). Los Angeles: Sage Publications.

Covey, S. R. (1990). Principle-Centered Leadership. New York: Free Press.

Creswell, J. (2007). Qualitative Inquiry \& Research Design, Chosing Among Five Approaches. Thousand Oakes: Sage Publications, Inc.

Cyert, R. \& March, J. (1959). A Behavioral Theory of Organizational Objectives. In Shafritz, J. M., Ott, J. S., \& Jang, Y. S. (Eds.), Classics of Organization Theory (6th ed.) (pp. 135-144). Belmont, CA: Wadsworth.

Demming, W. (1994). The New Economics. Cambridge: MIT, Center for Advanced Educational Services.

Department of the Navy, Washington, DC. (1990). United States Navy Regulations Chapter 8 [On-line]. Available: http://neds.daps.dla.mil/regs.htm.

Fossey, E., Harvey, C., McDermott, F., \& Davidson L. (2002). Understanding and Evaluating Qualitative Research [Electronic Version]. In Australian and New Zealand Journal of Psychiatry, 36, 717-732. Retrieved September 6, 2007, from Academic Search Premier database.

Gavin, B. (2003). Out of the chaos: Progression and Regression in the Workplace [Electronic Version]. Psychodynamic Practice, 9(1), (February 2003). Retrieved September 3, 2005, from EBSOhost. 
Giorgi, A. (1997). The Theory, Practice, and Evaluation of the Phenomenological Method as a Qualitative Research Procedure [Electronic Version]. Journal of Phenomenological Psychology, 28(2), 235-261. Retrieved September 6, 2007 from the Academic Search Premier database.

Ginsberg, A. \& Abrahamson, E. (1991). Champions of Change and Strategic Shifts: The Role of Internal and External Changed Advocates. Journal of Management Studies. 28(2). Retrieved November 19, 2007 from the Business Source Premier database.

Heifitz, R. A. \& Laurie, D. L. (1999). Mobilizing Adaptive Work: Beyond Visionary Leadership In J. A. Conger, G. M. Spreitzer \& E. E. Lawler III (Eds.), The Leader's Change Handbook: An Essential Guide to Setting Direction and Taking Action (pp. 55-86). San Francisco: Jossey-Bass.

Heifitz, R. A. \& Linsky, M. (2002). Leadership on the Line: Staying Alive Through the Dangers of Leading. Boston: Harvard Business School Press.

Herzberg, F. (1968). One More Time: How Do You Motivate Employees? Harvard Business Review, Jan-Feb, 53-62.

Johnson, G. (1990). Managing Strategic Change: The Role of Symbolic Action. British Journal of Management, 1, 183-200. Retrieved November 19, 2007 from the Business Source Premier database.

Kanter, R. (2004). Confidence: How Winning Streaks and Losing Streaks Begin and End. New York: Crown Business.

Kegan, R., \& Lahey, L. L. (2002). The Real Reason People Won't Change. In Harvard Business Review on Culture and Change (pp. 37-58). Boston: Harvard Business School Publishing Corporation.

Kennedy, D (2000). Clark will leave legacy of progress. In The Flagship, Hampton Roads, VA. [On line] Available: http://www.navy.mil/navydata/cno/covenant.html.

Kennedy, D. (2002). Navy's Future is Now [Electronic Version]. The Periscope 7/25/2002. Retrieved January 26, 2008 from www.kingsbayperiscope.com.

Kotter, J. P. (1990). What Leaders Really Do. Harvard Business Review. May-June, 103104.

Kotter, J. P. (1996) Leading Change. Boston: Harvard Business School Press.

Kotter, J. P. (2002) The Heart of Change. Boston: Harvard Business School Press.

Leadership Division, Naval Military Personnel Command (1985). Command Excellence: What It Takes to be the Best! Department of the Navy, Washington, DC. 
Levy, P. F. (2002). The Nut Island Effect: When Good Teams Go Wrong. In Harvard Business Review on Culture and Change (pp. 1-20). Boston: Harvard Business School Publishing Corporation.

Lippitt, L. L. (1998). Preferred Futuring. San Francisco: Berrett-Koehler Publishers, Inc.

Louis, M. (1980). Surprise and Sense Making: What Newcomers Experience in Entering Unfamiliar Organizational Settings. Administrative Science Quarterly. 25(2), 226252).

Martin, P. (2006). Changing the Leopard's Spots. Booksurge, LLC.

McGregor, D. (1957). The Human Side of Enterprise. In Shafritz, J. M., Ott, J. S., \& Jang, Y. S. (Eds.), Classics of Organization Theory (6th ed.) (pp. 179-184). Belmont, CA: Wadsworth.

McMichael, W. H. (2004). Skipper Set Tone for Carrier Turnaround [Electronic Version]. Navy Times, 4/26/04. Retrieved September 4, 2005 from www.navytimes.com.

McMichael, W. H. (2005). Navy IG: CO Firings Not Linked [Electronic Version]. Navy Times, 1/3/05. Retrieved September 4, 2005, from www.navytimes.com.

Meyerson, D. E. (2002). Radical Change the Quiet Way. In Harvard Business Review on Culture and Change (pp. 59-81). Boston: Harvard Business School Publishing Corporation.

Miles, M. \& Huberman, A. (1994). Qualitative Data Analysis: An Expanded Sourcebook. (2nd ed.). Thousand Oaks: Sage Publications.

Mintzberg, H. (1979). The Five Basic Parts of Organizations. In Shafritz, J. M., Ott, J. S., \& Jang, Y. S. (Eds.), Classics of Organization Theory (6th ed.) (pp. 219-230). Belmont, CA: Wadsworth.

Montor, K., McNicholas, T. Jr., Ciotti, A. Jr., Hutchinson, T III, and Wehmueller, J. (1998). Naval Leadership: Voices of Experience. (2nd ed.). Annapolis, MD: United States Naval Institute.

Morrow, S. (2005). Quality and Trustworthiness in Qualitative Research in counseling Psychology [Electronic Version]. In Journal of Counseling Psychology, 52(2), 250260. Retrieved September 6, 2007, from psychARTICLES database.

Munck, B. (2002). Changing a Culture of Face Time. In Harvard Business Review on Culture and Change (pp. 21-36). Boston: Harvard Business School Publishing Corporation. 
Nadler, D. (1999). A Success Story: The Case of Lucent Technologies. In J. A. Conger, G. M. Spreitzer \& E. E. Lawler III (Eds.), The Leader's Change Handbook: An Essential Guide to Setting Direction and Taking Action (pp. 3-25). San Francisco: Jossey-Bass.

National Defense Panel. (1997). Transforming Defense: National Security in the $21^{\text {st }}$ Century. Arlington, VA: National Defense Panel.

Pfeffer, J. (1981). Understanding the Role of Power in Decision Making. In Shafritz, J. M., Ott, J. S., \& Jang, Y. S. (Eds.), Classics of Organization Theory (6th ed.) (pp. 289-303). Belmont, CA: Wadsworth.

Quinn, R. E. (2000). Change the World. San Francisco: Jossey-Bass.

Rost, J. (1991). Leadership for the Twenty-First Century. New York: Praeger.

Schein, E. (1992). Organizational Culture and Leadership. (3rd ed.). San Francisco: Jossey-Bass.

Scutro, A (2007). Burke Skpper is Sixth CO Fired in Six Weeks. [Electronic Version]. Navy Times, 5/29/07. Retrieved May 26, 2009, from www.navytimes.com.

Selznik, P. (1948). Foundations of the Theory of Organization. In Shafritz, J. M., Ott, J. S., \& Jang, Y. S. (Eds.), Classics of Organization Theory (6th ed.) (pp. 125-134). Belmont, CA: Wadsworth.

Senge, P. M. (1990). The Fifth Discipline: The Art and Practice of the Learning Organization. New York: Doubleday.

Stavridis, J \& Mack, W. (1999). Command at Sea (5th ed.). Annapolis, MD: Naval Institute Press.

Strauss, A. (1987). Qualitative Analysis For Social Scientists. Cambridge, UK: Cambridge University Press.

Sull, D. N. (2002). Why Good Companies Go Bad. In Harvard Business Review on Culture and Change (pp. 83-106). Boston: Harvard Business School Publishing Corporation.

Trice, H. M. \& Beyer, J. M. (2005). Changing Organizational Cultures. In Shafritz, J. M., Ott, J. S., \& Jang, Y. S. (Eds.), Classics of Organization Theory (6th ed.) (pp. 383391). Belmont, CA: Wadsworth.

U.S.C. Title10, Subtitle C, Part II, Ch 551, Sec 5947 (Aug. 10, 1956). 
U.S. Department of Defense. (2001). Quadrennial Defense Review Report. Washington DC [On-line]. Available: http:/www.defenselink.mil/pubs/qdr2001.pdf.

Walton, M. S. (2004). Generating Buy-In: Mastering the Language of Leadership. New York: AMACOM.

Wertz, F. (2005). Phenomenological Research Methods for Counseling Psychology [Electronic Version]. In Journal of Counseling Psychology 52(2), 167-177. Retrieved September 6, 2007 from psychARTICLES database.

Zaleznik, A. (1977). Managers and Leaders: Are they Different? Harvard Business Review. 55(3), 67-80. Retrieved August 27, 2007 from the Business Source Premier database. 
Appendix A

Research Participant Consent Form 


\section{Research Participant Consent Form}

Leading Through Change:

\section{A Qualitative Study of the Experiences of Interim Commanding Officers}

Shoshana Chatfield is a doctoral student in the Leadership Department at the School of Leadership and Education Sciences at the University of San Diego and serves as an officer in the United States Navy at the rank of Commander. You are invited to participate in a research project she is conducting for the purpose of exploring leadership experiences of interim commanding officers.

The project will involve one interview that asks questions about your interim commanding officer experience and one or two short (5-15 minute) follow-up interviews. The interview will last about 60 minutes and also will include some questions about you, such as your age, years of military service, number and duration of command tours, and Myers Briggs Type Indicator (MBTI). The interview will take place at a time and place convenient for you. Participation is entirely voluntary and you can refuse to answer any question and/or quit at any time. Should you choose to quit, no one will be upset with you and your information will be destroyed right away. The researcher's rank should not influence your decision to volunteer to participate in this study. Officers lower in rank than the researcher are excluded from participating in the study and no officer under her positional authority will participate.

The information you give will be analyzed and studied in a manner that protects your identity. That means that a code number will be used and that your real name will not appear on any of the study materials. During the study, data and transcripts will be worked with on a password protected computer and backed up on a password protected 
disk. All information you provide will remain confidential and, when the study is complete, the data will be locked in a file cabinet in the Command Leadership School in Newport, RI for a minimum of five years before being destroyed.

Although the researcher will make every effort to protect confidentiality, the researcher cannot guarantee that someone very familiar with you and/or your situation will not be able to identify you. There may also be a risk that participating in the interviews may make you feel tired. Sometimes people feel anxious or sad when talking or reflecting on the things you will be asked about. If you would like to talk to someone about your feelings, you can call a local military chaplain or counselor at the following number: Miami Veteran Affairs Medical Center, (305) 325-7030. Remember, you can stop the interview at any time you feel tired or for any other reason.

The benefit to participating will be in knowing that you helped future interim commanding officers, and the senior navy officers responsible for assigning them, respond to leadership challenges during unscheduled succession.

If you have any questions about this research, please contact Shoshana Chatfield at (619) 368-5294, sho_chatfield@yahoo.com, or Faculty Advisor, Dr. Mary Scherr Ph.D., (619) 260-2274, scherr@sandiego.edu, at the University of San Diego. I have read and understand this form, and consent to the research it describes to me. I have received a copy of this consent form for my records. 
Signature of Participant

Name of Participant (Printed)

Signature of Principal Investigator

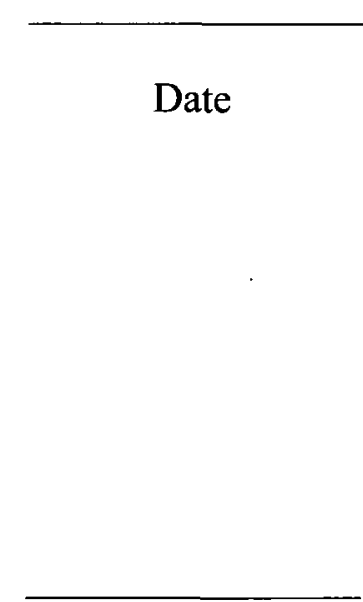

Date 
Appendix B

Framework for Interview 


\section{Framework for Interview}

All interviews will start with an open-ended question.

1. Tell me about your experience as an interim commanding officer...

The researcher will use the following open-ended questions to prompt additional dialogue during the interview.

2. What was it like when you found out you were selected as an Interim Commanding Officer?

a. How long did you have to prepare for the assignment?

b. Tell me about your trip to the location

c. Describe your arrival at the unit

3. What was it like to take command as Interim Commanding Officer?

a. What were you thinking about on the night before you took command as interim $\mathrm{CO}$ ?

b. Tell me about the day of your change of command.

c. Did you have goals for the unit on the day you took command? How/when did you develop them?

4. What were your perceptions about the wardroom?

5. What leadership behaviors did you find to be particularly effective as a commanding officer?

6. Talk about your interim command experience compared to your first command experience?

7. Is there anything else you would like to add? 
Appendix C

Framework of Interim Commanding Officer Experience 
Framework of Interim Commanding Officer Experience

\begin{tabular}{|c|c|c|}
\hline Phase & Actions/Interactions & Themes \\
\hline \multicolumn{3}{|l|}{ Arrival } \\
\hline $\begin{array}{l}\text { Awareness of the Event } \\
\text { and Notification }\end{array}$ & -Information Gathering & $\begin{array}{l}\text {-The unknown } \\
\text {-Confidence in self }\end{array}$ \\
\hline - Preparation & $\begin{array}{l}\text {-Information Gathering } \\
\text {-Travel }\end{array}$ & -Uncertain about situation \\
\hline $\begin{array}{l}\text { Incoming Assumption } \\
\text { of Command }\end{array}$ & $\begin{array}{l}\text {-Legitimization of interim } \\
\text { commanding officer } \\
\text {-Symbolic break with } \\
\text { previous commanding } \\
\text { officer and event causing } \\
\text { removal }\end{array}$ & $\begin{array}{l}\text {-Restoration of confidence } \\
\text { in command leadership }\end{array}$ \\
\hline \multicolumn{3}{|l|}{ Interim Command Leadership } \\
\hline - Immediate Actions & -Build Trust & -Trust \\
\hline - Assessment & -Gather Information & -Who can be trusted \\
\hline $\begin{array}{l}\text { - Identification of } \\
\text { Priorities and Focus } \\
\text { Areas }\end{array}$ & $\begin{array}{l}\text {-Model desired behavior } \\
\text {-Communication }\end{array}$ & $\begin{array}{l}\text {-Restore confidence in } \\
\text { operational safety, readiness } \\
\text { and mission ability }\end{array}$ \\
\hline $\begin{array}{l}\text { Promoting Cycles of } \\
\text { Transformation }\end{array}$ & $\begin{array}{l}\text {-Peeling back the onion } \\
\text { (addressing root causes) }\end{array}$ & $\begin{array}{l}\text {-Restore confidence in } \\
\text { standards and procedures }\end{array}$ \\
\hline \multicolumn{3}{|l|}{ Departure } \\
\hline $\begin{array}{l}\text { Outgoing Transfer of } \\
\text { Authority }\end{array}$ & $\begin{array}{l}\text {-Formal transfer of } \\
\text { authority without } \\
\text { ceremonial aspects }\end{array}$ & $\begin{array}{l}\text {-Confidence in return to } \\
\text { normal operations }\end{array}$ \\
\hline $\begin{array}{l}\text { - Internalization of the } \\
\text { Event }\end{array}$ & -Feelings of reward & $\begin{array}{l}\text {-Confidence in procedure } \\
\text {-Validation of ability }\end{array}$ \\
\hline
\end{tabular}


Apendix D

Justifications for Assignment of an Interim Commanding Officer 
Justifications for Assignment of an Interim Commanding Officer

\begin{tabular}{|c|c|}
\hline & Justification (raw data) \\
\hline \multirow{10}{*}{$\begin{array}{l}\text { Interim } \mathrm{CO} \\
\text { (confidence in own } \\
\text { ability) }\end{array}$} & $\begin{array}{l}\text { Able to bring principles with me (vision statement, principles for } \\
\text { cleanliness, safety, qualification) }\end{array}$ \\
\hline & I was pretty comfortable going into command \\
\hline & I was confident going into command \\
\hline & $\begin{array}{l}\text { I knew what I expected out of the crew whereas the first time } \\
\text { around you're kind of learning that }\end{array}$ \\
\hline & $\begin{array}{l}\text { I knew I knew exactly what these guys needed, or I thought I did, } \\
\text { and so I was confident about it. It was fun. So that was different, } \\
\text { I mean a little bit different, Not that it wasn't fun the first time, } \\
\text { but just going in having had that experience, it's really beneficial } \\
\text { I think }\end{array}$ \\
\hline & $\begin{array}{l}\text { I think it certainly helps if you've done the job before because } \\
\text { you have the experience and the background and the comfort } \\
\text { level to be thrown into that kind of environment }\end{array}$ \\
\hline & Plus I knew a lot about that ship from being a Deputy \\
\hline & I brought what got me through [1st unit], there to the ship. \\
\hline & $\begin{array}{l}\text { And, I could figure out on my own, there was probably about } \\
\text { three of us eligible. One being currency in the airplane was an } \\
\text { issue }\end{array}$ \\
\hline & $\begin{array}{l}\text { And I also felt that my experience that I gained commanding my } \\
\text { first [unit], I felt that I was well prepared to be able to go in and } \\
\text { help get the [unit] back on its feet and the crew back on its feet } \\
\text { because I had kind of had the similar experience with my first } \\
\text { command, the [unit] that was kind of the black sheep of the } \\
\text { [ISIC command] }\end{array}$ \\
\hline
\end{tabular}




\begin{tabular}{|c|c|}
\hline Theme & Justification (raw data) \\
\hline \multirow{4}{*}{$\begin{array}{l}\text { Selection of post- } \\
\text { command officer } \\
\text { (restoring crew } \\
\text { confidence in } \\
\text { leadership) }\end{array}$} & $\begin{array}{l}\text { you bring in a reputation of having been successful and knowing } \\
\text { what you're doing to the crew, so you're not going to get second- } \\
\text { guessed a lot like if you brought in somebody who was a first } \\
\text { CO. }\end{array}$ \\
\hline & $\begin{array}{l}\text { Some folks [need] to be removed, some folks just need a } \\
\text { different kind of leadership in front of them, some folks need to } \\
\text { be retrained, but the vast majority of them need someone who is } \\
\text { going to come in there, in the aftermath of this thing and restore } \\
\text { confidence that... you can trust him. He knows the mission, he } \\
\text { knows what we have to do to get the mission done, and he's } \\
\text { going to bring us home safe. }\end{array}$ \\
\hline & $\begin{array}{l}\text { I do believe that sending someone out there who, of course, is } \\
\text { capable, who has credibility in the eyes of the crew, but is } \\
\text { familiar, is a really good combination of things, if at all possible. }\end{array}$ \\
\hline & $\begin{array}{l}\text { having had the experience to command already, it wasn't as } \\
\text { traumatic as it might be for a first time CO stepping into it. }\end{array}$ \\
\hline \multirow[t]{3}{*}{$\begin{array}{l}\text { Selection of post- } \\
\text { command officer } \\
\text { (restoring crew } \\
\text { confidence in unit } \\
\text { readiness) }\end{array}$} & $\begin{array}{l}\text {...to make a break with what happened, why the CO was } \\
\text { relieved and what the impact to the officers and crew were as a } \\
\text { result of that, to try to put a dividing line between making sure } \\
\text { they understood where things had gone wrong and what their } \\
\text { role in that was, and how we can get better. }\end{array}$ \\
\hline & $\begin{array}{l}\text { But, that was probably the big thing to bring is those years of } \\
\text { experience }\end{array}$ \\
\hline & $\begin{array}{l}\text { And the key too was looking for a change in leadership and } \\
\text { getting a CO in there and get focused and get moved on }\end{array}$ \\
\hline
\end{tabular}




\begin{tabular}{|c|c|}
\hline Theme & Justification (raw data) \\
\hline \multirow{9}{*}{$\begin{array}{l}\text { Selection of post- } \\
\text { command officer } \\
\text { (organizational } \\
\text { confidence in } \\
\text { leadership) }\end{array}$} & known body of work \\
\hline & $\begin{array}{l}\text { you don't want to burden a first (time) } \mathrm{CO} \text { with something that } \\
\text { traumatic }\end{array}$ \\
\hline & reduced preparation time \\
\hline & $\begin{array}{l}\text { And, [the ISIC] was trying to evaluate whether or not to relieve } \\
\text { the XO to see whether or not he was part of the problem or part } \\
\text { of the solution. ...I only bridged the gap to continue the timing } \\
\text { for the XO. He relieved on time. But, where he normally would } \\
\text { have. So, I just bridged the gap. }\end{array}$ \\
\hline & $\begin{array}{l}\text { They were going to go with the experienced guy, rather than } \\
\text { sending the new PCO into an uncertain situation on [interim } \\
\text { unit]. It was probably the right decision. I don't know. I would } \\
\text { have done the same thing. }\end{array}$ \\
\hline & it's just a different perspective look \\
\hline & $\begin{array}{l}\text { I was asked that, you know, it's the classic, at the roundtable, } \\
\text { [deleted] ... and it gets into the classic, what's better? Fleet up or } \\
\text { direct install. I told them straight up, I said, direct install works } \\
\text { for that } 14 \text { weeks. But, I still support the fleet up program. Just } \\
\text { because, I think continuity is a big thing }\end{array}$ \\
\hline & $\begin{array}{l}\text { And I also think that you don't want to burden a first (time) } \mathrm{CO} \\
\text { with something that traumatic }\end{array}$ \\
\hline & $\begin{array}{l}\text { I think coming in new and not having any ownership, like you } \\
\text { would if you were the XO and becoming the CO this might be } \\
\text { more difficult, but coming in, fresh and from the outside, I think } \\
\text { provided a great opportunity to try to set a new course in some of } \\
\text { those areas for the [unit] that appeared to me needed a course } \\
\text { correction }\end{array}$ \\
\hline \multirow{2}{*}{$\begin{array}{l}\text { Selection of post- } \\
\text { command Deputy } \\
\text { from ISIC staff } \\
\text { (restoring } \\
\text { organizational } \\
\text { confidence in unit) }\end{array}$} & $\begin{array}{l}\text { [having a post command deputy...to] take care of things that } \\
\text { only the post command guy might have perspective on up to, and } \\
\text { including taking command of a ship on a short term basis if } \\
\text { necessary }\end{array}$ \\
\hline & $\begin{array}{l}\text { That's where it really helped being the former ISIC deputy, those } \\
\text { guys at [ISIC] knew I was going to come back to my job and } \\
\text { knew that they were going to work for me again. They totally } \\
\text { mobilized behind that stuff }\end{array}$ \\
\hline
\end{tabular}


Appendix E

Challenges of Interim Commanding Officers Grouped by Experience and Situation 
Challenges of Interim Commanding Officers Grouped by Experience and Situation

\begin{tabular}{|l|l|}
\hline Themes & Challenges described by Participants \\
\hline People (related to experience) & $\begin{array}{l}\text {-earning faith and trust } \\
\text {-overcoming antagonism }\end{array}$ \\
\hline People (related to situation) & $\begin{array}{l}\text {-readiness, personnel training } \\
\text {-dealing with and watching for a sense of } \\
\text { injustice about the findings of the } \\
\text { investigation (causes loss of trust in the } \\
\text { outside organization, squadron, group, etc., } \\
\text { could cause long term detrimental effect on } \\
\text { officers) }\end{array}$ \\
\hline Material Condition (related to situation) & $\begin{array}{l}\text {-material readiness } \\
\text {-underfunding }\end{array}$ \\
\hline The Unknown (related to experience) & $\begin{array}{l}\text {-unknown timeframe } \\
\text {-not knowing how long I would be there } \\
\text {-determining end state (what to accomplish } \\
\text { by turnover) }\end{array}$ \\
\hline Time (related to experience) & $\begin{array}{l}\text {-short time frame } \\
\text {-coming up to speed (personal qualification } \\
\text { and familiarity with unit) }\end{array}$ \\
\hline Pressure (related to situation) & $\begin{array}{l}\text {-pressure to keep to timetable (get ship } \\
\text { underway, participate in exercise or } \\
\text { mission, keep shipyard schedule) } \\
\text {-public scrutiny } \\
\text {-someone higher in chain of command } \\
\text { masking the seriousness of the status of the } \\
\text { unit } \\
\text {-"no absence of attention" from Navy } \\
\text { leadership }\end{array}$ \\
\hline $\begin{array}{l}\text { Cycles of Transformation (related to } \\
\text { situation) }\end{array}$ & $\begin{array}{l}\text {-move the crew past what had happened } \\
\text {-identifying what I thought the long term } \\
\text { causes were, if there were some (always } \\
\text { room for improvement) } \\
\text {-addressing long term causes with the crew } \\
\text { in a way they can accept it (not deny it and } \\
\text { shirk the truth) }\end{array}$ \\
\hline
\end{tabular}


Appendix F

Integration of Symptoms and Root Causes 
Integration of Symptoms and Root Causes

\begin{tabular}{|c|c|c|}
\hline Symptoms & Intermediate causes & Root Causes \\
\hline $\begin{array}{l}\text {-fragmented } \\
\text { wardroom } \\
\text {-"can do" culture } \\
\text {-hollow practices }\end{array}$ & $\begin{array}{l}\text {-Favoritism/perception of } \\
\text { favoritism } \\
\text {-lack of mentoring at lower } \\
\text { levels } \\
\text {-policy not guiding actions } \\
\text { (shortcuts, workarounds) } \\
\text {-pressure to maintain previous } \\
\text { success } \\
\text {-zero defect mentality } \\
\text {-lack of negative feedback }\end{array}$ & $\begin{array}{l}\text {-CO: Failure to develop talent } \\
\text {-CO: Failure to enforce } \\
\text { standards fairly } \\
\text {-Command Triad: Dysfunction } \\
\text { (involvement, ability) }\end{array}$ \\
\hline $\begin{array}{l}\text {-stigmatized crew } \\
\text {-bad ship mentality } \\
\text {-poor morale }\end{array}$ & $\begin{array}{l}\text {-incorrect policy } \\
\text {-policy not guiding actions } \\
\text {-degraded standards } \\
\text {-degraded enforcement of } \\
\text { standards } \\
\text {-Insufficient teamwork }\end{array}$ & $\begin{array}{l}\text {-CO: Absence/failure of } \\
\text { involvement } \\
\text {-CO: Failure to set policies } \\
\text {-Command Triad: Dysfunction } \\
\text { (involvement, ability, } \\
\text { qualifications) } \\
\text {-Navy: Under-investment }\end{array}$ \\
\hline -lack of ownership & $\begin{array}{l}\text {-poor material readiness } \\
\text {-poor personnel readiness } \\
\text {-policy not guiding actions } \\
\text { (remoteness factors) } \\
\text {-degraded standards } \\
\text {-absence of middle management }\end{array}$ & $\begin{array}{l}\text { CO: Failure to model } \\
\text { involvement behavior } \\
\text {-CO: Absence/failure to inspect } \\
\text {-CO: Failure to develop talent, } \\
\text { micromanaging } \\
\text {-Command Triad: Dysfunction } \\
\text { (division of responsibilities, } \\
\text { qualifications) }\end{array}$ \\
\hline -serious incident & $\begin{array}{l}\text {-incorrect policy/policy not } \\
\text { guiding actions } \\
\text {-degraded standards (remoteness } \\
\text { factors) } \\
\text {-pressure to sustain high tempo } \\
\text { operations } \\
\text {-pressure to maintain previous } \\
\text { success level } \\
\text {-zero defect mentality } \\
\text {-decisions made at wrong level } \\
\text {-perceived pressure from higher } \\
\text { levels of leadership }\end{array}$ & $\begin{array}{l}\text {-CO: Judgment } \\
\text {-CO: Failure to set policy } \\
\text {-CO: Absence/failure to inspect } \\
\text {-Command Triad: Dysfunction } \\
\text { (influence) }\end{array}$ \\
\hline -failed inspection & $\begin{array}{l}\text {-poor material readiness } \\
\text {-poor personnel readiness }\end{array}$ & $\begin{array}{l}\text {-CO: Failure to set priorities } \\
\text {-CO: Failure to model } \\
\text { involvement behavior } \\
\text {-Command Triad: Dysfunction } \\
\text { (involvement, ability) } \\
\text {-Navy: Under-investment }\end{array}$ \\
\hline
\end{tabular}


Appendix G

Described Behaviors of Interim Commanding Officers 
Described behaviors of Interim Commanding officers

\begin{tabular}{|c|c|c|}
\hline Goal & Skill & Action/Interaction \\
\hline \multirow[t]{4}{*}{$\begin{array}{l}\text { Restoring } \\
\text { Confidence }\end{array}$} & Modeling (behavior) & $\begin{array}{l}\text { Lead by example } \\
\text { Learning to operate ship } \\
\text { Studying manuals, procedures } \\
\text { Being hands on } \\
\text { Demonstrating positive attitude/ up beat } \\
\text { Confronting problems } \\
\text { showing a positive attitude }\end{array}$ \\
\hline & Modeling (involvement) & $\begin{array}{l}\text { Lead by example } \\
\text { Providing oversight } \\
\text { holding people accountable (supervising) } \\
\text { inspecting, interviewing looking at material } \\
\text { condition (understanding what's going on) } \\
\text { Being present (wardroom, camaraderie) } \\
\text { Eating meal in wardroom }\end{array}$ \\
\hline & Modeling (Standards) & $\begin{array}{l}\text { Setting example } \\
\text { Increasing credibility (by example, by the } \\
\text { book, standards) } \\
\text { holding people accountable (disciplining) }\end{array}$ \\
\hline & Building trust & $\begin{array}{l}\text { Being approachable } \\
\text { Staying on message } \\
\text { Putting people at ease } \\
\text { Getting to know the guys } \\
\text { Communicating trust } \\
\text { Sleeping off the ship (mitigating effects on } \\
\text { crew) } \\
\text { Delegating } \\
\text { Providing oversight (operational safety) } \\
\text { Attending events } \\
\text { Being present } \\
\text { Being accessible } \\
\text { Learning from mistakes } \\
\text { Telling sea stories (open communication } \\
\text { education) } \\
\text { Developing inspirational symbols } \\
\text { treating people fairly } \\
\text { being honest } \\
\text { balancing time } \\
\text { stating expectations } \\
\text { communicating appreciation } \\
\text { establishing meetings (information sharing) } \\
\text { (planning), (wrap up) } \\
\text { walking the talk } \\
\text { Empowering }\end{array}$ \\
\hline
\end{tabular}




\begin{tabular}{|c|c|}
\hline & Promoting open communication \\
\hline $\begin{array}{l}\text { Developing } \\
\text { Subordinates }\end{array}$ & $\begin{array}{l}\text { Delegating } \\
\text { Increasing cohesiveness of command triad } \\
\text { Mentoring-performance debrief } \\
\text { Developing others }\end{array}$ \\
\hline Emotional management & $\begin{array}{l}\text { Empathizing } \\
\text { Encouraging } \\
\text { Counseling } \\
\text { Reassuring } \\
\text { informing }\end{array}$ \\
\hline $\begin{array}{l}\text { Communicating } \\
\text { (sending) }\end{array}$ & $\begin{array}{l}\text { Talking to crew carefully } \\
\text { Never losing temper without a plan } \\
\text { Communicating philosophy (verbal, written, } \\
\text { during check in) } \\
\text { Giving feedback } \\
\text { communicating standards } \\
\text { Posting command philosophy } \\
\text { Calling an all khaki meeting } \\
\text { showing, illustrating (educating) } \\
\text { sending a letter/email identifying needs } \\
\text { talking to the crew } \\
\text { Educating } \\
\text { Informing } \\
\text { Reassuring } \\
\text { Recognizing crew } \\
\text { communicating standards } \\
\text { Correspondence-email (verifying } \\
\text { interpretation of something) } \\
\text { Having a conversation with wardroom } \\
\text { (educating) } \\
\text { Counseling (educating) }\end{array}$ \\
\hline $\begin{array}{l}\text { Communicating } \\
\text { (receiving) }\end{array}$ & $\begin{array}{l}\text { Talk to DH (info gathering) } \\
\text { Interviewing DH, Officers (assessing) } \\
\text { Sit around table and talk } \\
\text { Making small changes (listening to the crew) } \\
\text { Understanding }\end{array}$ \\
\hline $\begin{array}{l}\text { Educating/Interpreting } \\
\text { context }\end{array}$ & Counseling \\
\hline
\end{tabular}


Appendix $\mathrm{H}$

Advice for Interim Commanding Officers 
Advice for Interim Commanding Officers:

Mitigating Challenges of the Assignment

Arrival Phase

The arrival phase should be dominated by self-preparation and information gathering. Concentrate on getting qualified and receiving information from people your trust as well as key stakeholders in the unit's leadership and support structure.

\section{Limited time.}

(a) schedule briefings from ISIC staff members, phone briefings if necessary

(b) obtain copy of investigation

(c) list ideas, programs and areas of concern during travel

(d) list people you know who can act as trusted agents at the unit

(e) consider identifying an executive assistant

Knowledge: "coming up to speed".

(a) tour unit with Senior Enlisted Advisor

(b) read investigation and use results or conclusions of investigation as a data point in your own assessment

(c) talk to people you know you can trust

Personal qualifications and certifications.

(a) request training team travel to unit location to provide instruction/certification

(b) meet with port operations authorities

(c) meet with experts navigating local waters

(d) review charts, maps and tide issues with local experts

(e) regain currency in aircraft 
(f) recertify on reactor

Meeting with appropriate higher leaders.

(a) meet with unit's ISIC or Deputy

(b) meet with Operational Commander and/or Deputy

(c) meet with Type Commander

(d) meet with Fleet Commander

(e) receive briefings as needed from systems commands

(f) from higher authority, gain approval of information about investigation of the incident that is releasable to crew and families

Addressing needs and concerns of crewmember spouses / families.

(a) if time allows schedule meeting with spouses, otherwise specifically delegate this to ISIC staff

(b) conduct Town Hall Meeting with spouses

(c) address concerns about vacation plans and money already spent on holiday leave

(d) keep families informed about homeport changes so they can plan for moves and schooling for children

(e) ask spouse to engage with spouses clubs and families

(f) establish relationship with Ombudsman

(g) hire new Ombudsman if needed

(h) ask ISIC to meet with spouses and families to pass information personally

(i) ask ISIC to facilitate availability of counseling services to families 
(j) beware of passing mis-information or not passing information, consequences are disastrous

Own family concerns.

(a) discuss assignment with spouse to determine her willingness to engage in traditional spouse duties with families and spouses of crew

Impact on own career timing.

(b) discuss with personnel manager (formal communication if necessary)

(c) discuss with ISIC

\section{Leadership Phase}

Dealing with unknown duration of command.

(a) avoid short term focus (avoids transmitting uncertainty and confusion to the crew and their families)

(b) determine desired end state including short, medium and long term unit goals

(c) develop a product containing observations, assessments and recommended way forward for next commanding officer

Determining who to trust.

(a) utilize trusted agent to expand visibility over Departments and Department Heads

(b) work closely with XO and Senior Enlisted Advisor to validate effectiveness of command triad

(c) validate reports

(d) communicate standards

(e) personally inspect processes and outcomes 


\section{Making sure to get it right.}

(a) select trusted agent (formal or informal)

(b) determine suitability of XO and SEA

(c) hire new XO or SEA if needed

(d) schedule ISIC or ISIC staff members for pre-inspections or underway periods

(e) assess safety first and immediately take action to correct procedures and policies

Dealing with pressure:

Pressure (to get underway, deploy, get the unit ready for war or mission) from higher leadership might be extreme due to impact on Exercises, Operational Mission or perceptions about unit's location (foreign port).

(a) request delay

(b) break down operational imperative to validate key safety and readiness measures of effectiveness prior to mission

(c) recognize achievements of the crew upon reaching key milestones

Providing for emotional management of crew (trauma from incident).

(a) work closely with command triad to keep crewmembers out of trouble. Anticipate problems, especially disciplinary problems and alcohol abuse.

(b) conduct focused interviews to assess whether or not there is anybody who is mentally not in the game, needs to be replaced, needs to step down or can't stand watch

(c) request assist visit from mental health professional for assessment and services 
(d) develop programs designed to help prevent anticipated alcohol abuse

(e) implement a healthy lifestyles program emphasizing outdoor activities and no alcohol

\section{Restoring Confidence}

By stating and reinforcing standards and improving perceptions of fairness, you will best promote confidence in the changes that you desire to implement. Focus on modeling desired behaviors and on promoting open communication.

Build trust with leadership team.

(a) build trust with leadership team (Command Triad: CO, XO, SEA) and get buy in about open communication and solidarity in front of the crew

(b) communicate standards

(c) balance the team

(d) remove proxy members from command triad processes (other members from the crew who may have been compensating for dysfunction within the command triad)

Build trust with unit senior and middle managers.

(a) assess senior and middle managers: Dept Heads, Chief Petty Officers, Wardroom

(b) replace members who do not have the energy or talent to move the unit forward

(c) communicate standards and expectations directly to all leadership tiers 
(d) fire or transfer people whose actions, behaviors or attitudes are blocking unit leadership from accomplishing the interim commanding officers priorities and unit goals

(e) hire the right people with the right skills for key target areas (temporarily if necessary when time needed to identify and train a normal replacement)

(f) lead by example (level of involvement)

(g) lead by example (attitude)

(h) lead by example (setting and enforcing standards and accountability)

(i) lead by example (inspecting processes, inspecting material condition) Build trust with the crew.

The crew must understand that you have confidence in them and in their ability. Be deliberate in your acknowledgement of the crew's proficiency and success. It will be difficult to manage building trust with the crew to reduce their perception that you are an outsider. You must balance the pace that you implement change and educate the crew with the actions that you take to build trust. Above all you must be modeling the behaviors you desire.

(a) lead by example (modeling behavior)

(b) communicate standards

(c) listen to the crew

(d) inspect results

(e) demonstrate fairness with discipline

(f) educate during discipline 
(g) avoid scapegoating: don't disciple a single crewmember when the problem is systemic

Providing for emotional management of crew (discipline from incident, loss of career opportunity).

(a) be honest in counseling about impact of discipline on career

(b) treat fairly and reestablish trust

Minimize impact of $\mathrm{CO}$ removal on crew.

(a) understand that it is already a change for the crew that you're coming in

(b) limit amount of change the crew feels

(c) commit command triad to differentiating between necessary change and preferred change

(d) avoid saying "you guys" or any other phrase that sets them apart from you and your standards and goals

Reversing bad morale (bad ship mentality, failed inspection, public report of failure).

(a) maintain positive attitude

(b) engage the chief's mess

(c) reward accomplishment of short term goals

(d) allow time off

(e) only allow deliberate (calculated) display of anger

(f) wait for turnaround in the crew

(g) organize a public affairs victory (ensure wins are reported publicly)

Educating crew about their part in the incident. 
The wardroom, Chiefs Mess and/or crew might feel that the investigation concluded with findings that were not accurate. Their perception of being misunderstood and mistreated by the larger Navy organization might affect their willingness to buy into new standards and procedures. It could also have a lingering affect on their trust in the Navy as a whole.

(a) determine releasable information

(b) conduct presentation of facts at all hands call

(c) balance communicating trust in the crew and finding the right time and right way to bring changes

(d) establish and communicate standards

(e) avoid using individuals as scapegoats (making an example of one person when a team, department, or system is deficient)

(f) involve Department Heads in development of individual and team training milestones

(g) listen to the Chief's Mess

(h) provide feedback on Department Head performance

\section{Departure Phase}

Include an assessment about the crew and symptoms and root causes you may have discovered affecting command climate in your turnover to the prospective commanding officer. Avoid the desire to melt away without a change of command ceremony. Your departure signals the return to a normal condition for the unit and is extremely important for the crew to see and acknowledge. They need to see the formality of the official transfer of authority. It is appropriate to dress down the occasion without 
using formal dress uniform or including other ceremonial aspects of a change of command ceremony. Call the troops to muster. Acknowledge and praise their accomplishments. Include the reading of the orders in the recognizable format. Hand over the unit to its new commanding officer, then fade away.

(a) in addition to normal turnover, include root cause assessment for the prospective commanding officer

(b) conduct change of command ceremony, include calling troops to muster and reading of orders

(c) complete symptoms and root causes survey

(d) schedule debrief of experience with ISIC 